\title{
Kinetics pathway of precipitation in model Co-Al-W superalloy
}

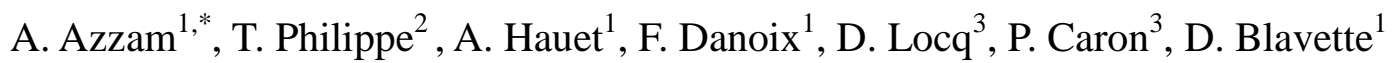 \\ ${ }^{1}$ Normandie Université, UNIROUEN, INSA Rouen, CNRS, GPM, 76800 Saint Etienne du \\ Rouvray, France \\ ${ }^{2}$ Physique de la Matière Condensée, Ecole Polytechnique, CNRS, 91128 Palaiseau, France \\ ${ }^{3}$ ONERA - The French Aerospace Lab, F-92320 Châtillon, France
}

\begin{abstract}
:
The early stages of precipitation of the $\gamma^{\prime}$ phase in a model Co based superalloy (Co-9.1Al$7 \mathrm{~W}$ (at.\%)) have been investigated at $900{ }^{\circ} \mathrm{C}$ using electron microscopy and atom probe tomography. Nucleation, growth and coarsening stages have been studied with a focus on the temporal evolution of the precipitate composition in the light of recent theoretical developments on phase separation in multicomponent alloys. The experimental data have been confronted to the theories of nucleation and coarsening recently developed for such alloys, which are valid for non-ideal and non-dilute systems, and predict the temporal evolution of both the matrix and precipitate compositions. The rate constant for the mean size evolution of the particles, as derived from experiments, has been compared to the one predicted by the mentioned coarsening theory that accounts for a more accurate description of the thermodynamics of the phases, as compared with more classical approaches. From this comparison the $\gamma / \gamma^{\prime}$ interfacial energy was derived and found equal to $\sim 48 \mathrm{~mJ} / \mathrm{m}^{2}$. the exponents for the temporal evolution of average particles size, number of particles per unit volume were found identical to those for binary alloys during the coarsening regime, as expected, and the temporal evolutions of compositions in both $\gamma$ and $\gamma^{\prime}$ phases were found to evolve as predicted by theory. Indeed, the $\mathrm{W}$ content in the particles, measured from atom probe tomography (APT) experiments, was found to significantly decrease with time and the observed evolution is remarkably well described by the theory and therefore is shown to originate from the competition between diffusion and capillarity.
\end{abstract}

Key words: precipitation, Co-Al-W superalloys, coarsening, ternary alloys, atom probe tomography, transmission electron microscopy, scanning electron microscopy

* Corresponding author: ahmad.azzam@etu.univ-rouen.fr 


\section{INTRODUCTION}

For more than 60 years, $\mathrm{Ni}$ based superalloys are key materials for high temperature applications in aerospace, in particular for aircraft engines. These superalloys derive their excellent mechanical properties at temperatures exceeding $800{ }^{\circ} \mathrm{C}$ from the presence of a high volume fraction of coherent $\mathrm{L1}_{2^{-}} \gamma^{\prime}$ precipitates dispersed in a disordered FCC- $\gamma$ matrix. In 2006, Sato et al. [1] discovered the existence of a small $\mathrm{L}_{2}$ coherent $\gamma^{\prime}\left(\mathrm{Co}_{3}(\mathrm{Al}, \mathrm{W})\right)$ domain in the CoAlW ternary phase diagram, with average composition of about 9.5 at $\% \mathrm{Al}$ and 13 at $\% \mathrm{~W}$. As a consequence, a $\gamma-\gamma^{\prime}$ region exists in the ternary alloy. According to Sato, this two phase $\gamma-\gamma^{\prime}$ region extends from 9.2 to 10 at.\% for $\mathrm{Al}$ and from 5.4 to 12 at.\% for $\mathrm{W}$. The existence domain of this two phase region is rather narrow in terms of $\mathrm{Al}$ content, whereas there is a larger variability in W. It is therefore possible to consider this ternary system as a pseudo-binary one, and to define low supersaturation alloys, when the $\mathrm{W}$ content is close to the $\gamma$ limit of the domain ( $\mathrm{W}<7$ at.\%), and high supersaturation alloys when it is close to the $\gamma^{\prime}$ limit (W > 9 at.\%). The existence of the two phase region opened the route to the development of a new generation of cobalt based superalloys, hardened by coherent $\gamma^{\prime}$ $\mathrm{Co}_{3}(\mathrm{Al}, \mathrm{W})$ intermetallic precipitates, dispersed in the Co-rich FCC $\gamma$ parent phase. From there, this new generation of Co based superalloys, with a higher melting temperature than $\mathrm{Ni}$ based superalloys, is regarded as a promising candidate for high temperature applications. Indeed, many subsequent studies have shown that they exhibit good mechanical properties and creep resistance at high temperature, comparable to those observed in the $\mathrm{Ni}$ based superalloys [2-6]. Partitioning behavior of solute elements (W, Al...) has been studied by several groups by using APT and transmission electron microscopy (TEM) [11-15]. W was found to strongly partition to the $\gamma$ ' phase, whereas partitioning of Al was observed to be much weaker in the $\gamma^{\prime}$ phase, contrary to what is observed in Ni based superalloys in which $\gamma^{\prime}$ precipitate composition is based on $\mathrm{Ni}_{3} \mathrm{Al}$ stoichiometry. This partitioning behavior of solute 
elements is in good agreement with the prediction of the phase diagram proposed by Sato et

However, one of the main issues in the development of Co based superalloys is the stability of the $\gamma^{\prime}$ phase, that was shown to become instable at temperatures exceeding $800^{\circ} \mathrm{C}[7-10]$. Therefore, information on the temporal evolution of microstructure and on the kinetics of precipitation of $\gamma^{\prime}$ precipitates is of utmost importance for the optimization of heat treatments, and alloy composition. Early stages of $\gamma-\gamma^{\prime}$ phase separation are also very interesting from a fundamental point of view, as will be shown later.

Kinetics of precipitation in the ternary CoAlW system was first studied by Meher et al.[12] in the highly supersaturated Co-10W-10Al (at.\%) alloy. Precipitates were shown to form during quenching. The presence of $\gamma^{\prime}$ precipitates indicates that the driving force to form $\gamma^{\prime}$ precipitates, even during the quench, is very high, making the early stages of phase separation difficult to study. Nucleation, and early stages of growth, could not be observed, and only coarsening during ageing was investigated. These results were confronted to the modified form of the classical LSW model developed by Calderon et al. [17-18] for non-dilute solution. The authors showed that the temporal evolution of average precipitate size, as measured by their mean radius R, agrees well with the classical LSW coarsening model [17-18,20], with a linear dependence of $\mathrm{R}^{3}$ on ageing time. The composition of both phases was measured by APT. The evolution of $\mathrm{W}$ and $\mathrm{Al}$ content in both phases was not found to change over time. The $\gamma / \gamma^{\prime}$ interfacial energy $(\sigma)$ was derived from APT data and found to be $10 \mathrm{~mJ} / \mathrm{m}^{2}$ and 19 $\mathrm{mJ} / \mathrm{m}^{2}$ at $800^{\circ} \mathrm{C}$ and $900^{\circ} \mathrm{C}$ respectively. These values of $\sigma$, which are typical of coherent interfaces, are close to those observed in model NiAlCr nickel based superalloys [19-21]. Similarly, kinetics of precipitation has also been examined by Sauza et al. [22] and Vorontsov et al. [23] in low supersaturated Co-8.8Al-7.3W at.\% and Co-7Al-7W at.\% alloys respectively, using scanning electron microscopy (SEM). The average size of $\gamma^{\prime}$ particles (R) 
was observed again to follow the LSW coarsening law $\left(\mathrm{R}^{3} \sim \mathrm{t}\right)$. The number density of $\gamma^{\prime}$ precipitates was found to decrease with time according to a $\mathrm{t}^{-1}$ kinetic, also in agreement with the classical predictions [17-18,20,24]. But no chemical information regarding $\gamma$ and $\gamma^{\prime}$ phase was given in these low supersaturated alloys.

The present study is aiming at filling this gap through the APT and electron microscopies (TEM-SEM) investigation of the precipitation kinetics in a low supersaturated alloy, with particular interest in following the chemical evolution of both phases. In this work, and in contrast to previous studies, a low supersaturated CoAlW alloy (Co-9.1Al-7W at.\%), with expected lower volume fraction of $\gamma^{\prime}$ precipitates and driving force, was studied in order to tempt to investigate the first stages of phase separation at $900{ }^{\circ} \mathrm{C}$. These original data will be confronted with the most recent theory of phase transformation in ternary systems.

This new model, predicts that, for short aging times, the $\gamma^{\prime}$ phase composition may deviate from its final equilibrium value. This non-classical behavior is a result of the competition between capillarity effects and coupling effect in diffusion process [25]. The predictions of this model have already been validated in $\mathrm{NiCrAl}$ alloy [59], and will be discussed here for CoAlW alloys. Interfacial segregation energy will also be derived from this model.

To sum up, the main objectives of this work, are :

a- Studying the early stages of precipitation during isothermal ageing at $900^{\circ} \mathrm{C}$ in terms of morphology, number density, size and volume fraction of $\gamma^{\prime}$ precipitates

b- Following the temporal evolution of composition of $\gamma$ and $\gamma^{\prime}$ phases, as derived from APT experiments.

c- Confronting the temporal evolution of phase composition as derived from theory to experiments. 
d- Estimating the interfacial energy from recent nucleation and coarsening theories for multicomponent systems.

\section{EXPERIMENTAL}

Polycrystalline ingots of a ternary Co base alloy with a diameter of $8 \mathrm{~mm}$ and $60 \mathrm{~mm}$ in length were prepared in a vacuum induction melting furnace at the office national d'études et de recherches aérospatiales (ONERA), France. The target composition was Co-9.1Al-7W (at.\%) after solidification. Ingots were subjected to a homogenizing heat treatment at $1300{ }^{\circ} \mathrm{C}$ followed by water quenching. To limit possible precipitation of $\gamma^{\prime}$ during the quench, all heat treatments were performed on thin samples (thickness $300 \mu \mathrm{m}$ ) under argon atmosphere. Samples were subsequently aged at $900^{\circ} \mathrm{C}$ for $5 \mathrm{~min}, 15 \mathrm{~min}, 1 \mathrm{hr}, 10 \mathrm{hrs}, 100 \mathrm{hrs}$ and $200 \mathrm{hrs}$ under argon atmosphere in a vertical furnace, and then water quenched. The grain size measured by electron backscattered diffraction (EBSD) was around $100 \mu \mathrm{m}$.

The alloy microstructure was investigated by SEM (Zeiss Leo 1530 XB) and TEM (Jeol 2010) operated at $200 \mathrm{kV}$. Samples for SEM were mechanically grounded and then electropolished in a solution of methanol with $5 \%$ perchloric acid, at a temperature of $-40{ }^{\circ} \mathrm{C}$ and a voltage of $18 \mathrm{~V}$. For TEM analyses, discs of $3 \mathrm{~mm}$ in diameter were cut and mechanically polished to a thickness less than $100 \mu \mathrm{m}$ and then thinned to electron transparency in a twin jet polishing system (TenuPol-5) with the same solution and conditions as above.

APT was run in voltage mode, rather than in laser mode. Pulsed laser APT was developed originally for the investigation of bad conductors such as semiconductors and oxides [26]. Although using laser pulses improves the life time of specimens during analyses, laser mode has the disadvantage of giving rise to more complex APT mass spectra (more molecular ions) that are trickier to interpret. Also, and independently, reliability issues may occur in composition measurements. We compared both pulse modes, and concluded that voltage 
mode gives more reproducible data. As shown in Fig. 1, the mass spectra obtained using voltage pulses are unambiguous, with a reduced number of mass peaks, easy to assign to the main elements.

Samples for APT were prepared using focused ion beam (Zeiss Nvision 40 FIB-SEM) and lift out method. Initial annular milling was performed with an accelerating voltage of $30 \mathrm{kV}$. The final step was carried out with a low voltage $(2 \mathrm{kV})$ to reduce damage caused by the Ga ions [27-29]. APT experiments were carried out using a local electrode atom probe (LEAP 4000 $\mathrm{HR}{ }^{\circledR}$, Cameca instrument) in voltage mode, with a pulse frequency of $200 \mathrm{KHz}$, a pulse fraction of $20 \%$ of the standing voltage, and a detection rate of $0.2 \%$ ion/pulse. APT data were treated using IVAS (version 3.6.8) software. The tip was maintained at a relatively elevated temperature $(80 \mathrm{~K})$ in order to reduce the applied field, and avoid premature fracture of the analyzed sample.

The influence of specimen temperature on measured alloy compositions was checked for different temperatures, and is summarized in table 1. No significant evolution in the measured values has been observed, showing that preferential evaporation which is known to increase with specimen temperature [30] can be neglected at $80 \mathrm{~K}$. The average overall composition of the alloy in the as-quenched state was found to be close to Co-10.16 $\pm 0.09 \mathrm{Al}-7.88 \pm 0.10 \mathrm{~W}$ at.\%, from more than twenty analyses in the as quenched condition. The measured composition is slightly richer in solute elements than the target composition Co-9.1Al-7W at.\%. The overall composition was also measured by energy dispersive X-ray spectroscopy (EDS). The measured composition is close to Co-9.3 $\pm 0.35 \mathrm{Al}-7.4 \pm 0.15 \mathrm{~W}$ at. $\%$, confirming that the alloy is slightly richer in solute elements than expected.

\section{RESULTS}




\section{Quenched state}

In contrast to SEM, which failed to reveal any other phase than the parent $\gamma$ phase, TEM exhibited diffraction features revealing the presence of a second phase. Diffraction pattern taken along the [100] zone axis (Fig. 2a) show superlattice spots, indicating that a $\mathrm{L}_{2}$ ordered phase has formed during quenching. Fig. $2 b$ is a dark field TEM micrograph taken from the superstructure (010) spot. $\mathrm{L}_{2}$ ordered zones are observed, with a size of about 3 to $8 \mathrm{~nm}$. In order to proof that these zones are $\gamma^{\prime}$ precipitates, with a distinct chemical composition compared to $\gamma$ phase, and not equi-composition $\mathrm{L}_{2}$ ordered zones due to congruent ordering during quench [31], APT investigations were carried out (Fig. 3). Whereas the Co map exhibits an inhomogeneous distribution of this element, surprisingly no apparent partitioning of $\mathrm{W}$ and $\mathrm{Al}$ is observed (Fig. $3 \mathrm{~b}$ and $3 \mathrm{c}$ ). Concentration profiles and atomic density profiles were derived from $3 \mathrm{D}$ reconstruction by moving a small sampling box $\left(2 \times 2 \times 2 \mathrm{~nm}^{3}\right)$ containing $250 \pm 30$ atoms along the tip axis. Unlike atom maps, concentration profiles (Fig. 3d) clearly exhibit $\mathrm{W}$ and $\mathrm{Al}$ enriched zones. Obviously, $\mathrm{W}$ and $\mathrm{Al}$ enriched domains are $\mathrm{Co}$ depleted, which is the signature of phase separation between $\gamma$ and $\gamma^{\prime}$ phases. Although no contrast appeared in $\mathrm{W}$ and $\mathrm{Al}$ maps, $\gamma^{\prime}$ precipitates are therefore present. This paradox comes from the competition between the so-called local magnification effect and the existence of $\mathrm{W}$ enriched $\gamma^{\prime}$ zones. An atomic density profile (atoms per sampling box) is also displayed in Fig. 3d. The density profile clearly shows low atomic density zones correlated with W-enriched regions $(\sim 8 \mathrm{~nm})$ (Fig. 3d). Low atomic density zones are due to defocusing effects. $\mathrm{W}$ is known to be a high evaporation field element [32]. Consequently, W-enriched precipitates have a higher evaporation field compared to that of the surrounding $\gamma$ matrix. High-field precipitates will develop a smaller local radius of curvature, leading to defocusing effects in the ion trajectories originating from the high field region, explaining the lower local atomic density regions. This is the reason why the atomic map of $\mathrm{W}$ (Fig. $3 \mathrm{~b}$ and 3c) do not clearly 
exhibit the presence of $\mathrm{W}$-enriched regions in Fig. 3c although $\mathrm{W}$-enriched precipitates are concentration) is counterbalanced by the lower impact density due to local magnification effect (defocusing). This clearly confirms that bright zones observed in dark field TEM micrographs with an average size close to $8 \mathrm{~nm}$ (Fig. 2b) are small W-enriched nanoprecipitates that nucleated during quenching from $1300^{\circ} \mathrm{C}$. These precipitates are also enriched in $\mathrm{Al}$ but in less extend, as expected.

Apparently, the $\mathrm{W}$ and $\mathrm{Al}$ content in $\gamma^{\prime}$ regions evaluated from composition profiles (Fig 3(d)), are close to $12.0 \pm 3.3$ at.\%. Because of local magnification effects, trajectory overlaps occur close to $\gamma / \gamma^{\prime}$ interfaces. Co ions coming from the surrounding matrix may therefore fall in the $\gamma^{\prime}$ regions on the detector, leading to an overestimation of Co in $\gamma^{\prime}$ regions. Although this effect cannot be ruled out, it is marginal as the atomic fraction of Co in $\gamma^{\prime}$ precipitates (75.0 \pm 4.4 at.\%, Fig. 3d) appears to be very close to 75 at.\%, the expected stoichiometry of the $\mathrm{L1}_{2} \mathrm{Co}_{3}(\mathrm{Al}, \mathrm{W})$ phase. Statistical fluctuations on local concentration assessment, caused by sampling errors, are twice the standard deviation $\sigma$, with $\sigma=\left[C_{i}\left(1-C_{i}\right)(1-Q) / N\right]^{1 / 2}$ where $\mathrm{C}_{\mathrm{i}}$ is the concentration of species $\mathrm{i}, \mathrm{N}$ the number of atoms in the sampling box $(250 \pm 30)$ and $\mathrm{Q}$ is the detection efficiency $(\sim 36 \%))$ [33].

\section{Microstructural evolution at $900^{\circ} \mathrm{C}$}

Preliminary SEM observation failed to show any new phase at the grain boundaries (GBs) or in the core of grains for ageing at $900{ }^{\circ} \mathrm{C}$ up to $10 \mathrm{hrs}$. After $100 \mathrm{hrs}$ ageing precipitates were visible at some grain boundaries (Fig. 4). These were identified by $\mathrm{EDS}$ as $\mathrm{D}_{19} \mathrm{Co}_{3} \mathrm{~W}$ precipitates. $\mathrm{D} 0_{19}$ is a stable phase that may form in binary Co-W alloys and is present in the Co-Al-W phase diagram [1]. TEM images related to ageing from 5 min up to $200 \mathrm{hrs}$ were taken far from such $\mathrm{D}_{19}$ decorated GBs so that to follow $\gamma^{\prime}$ precipitation (Fig. 5 and 6). 
Dark field TEM micrographs show the presence of numerous $\gamma^{\prime}$ precipitates that develop during ageing. No small secondary precipitates are observed between the primary $\gamma^{\prime}$. Drastic changes in morphology and microstructure are evidenced. In the early stages of ageing (Fig. 5a), the $\gamma^{\prime}$ precipitates are nearly spherical. The coherency elastic strain is proportional to the precipitate volume (proportional to $\mathrm{R}^{3}$ ) and anisotropies from this are thought to be negligible in the early stages. We can also observe that there is no preferential alignment of $\gamma^{\prime}$ precipitates at this stage of growth. When particles grow their shape changes from spherical to cuboidal (Fig. 5b, 5c and 5d), due to the dominant contribution of the coherency strain energy that increases as $\mathrm{R}^{3}$ compared to interface energy that increases as $\mathrm{R}^{2}$. For prolonged ageing times, a change of the shape to rectangular-like morphologies aligned along the soft $\langle 001\rangle$ directions is evidenced in Fig. 6a and 6b [34]. In the following, when dealing with cuboidal precipitates, the radius $R$ of the spherical particles is replaced by the half-edge length $(d / 2)$ of cuboids. An alignment of $\gamma^{\prime}$ precipitates is observed, forming elongated colonies. These "colonies" are separated by dark $\gamma$ corridors. For long ageing times, coarsening is observed but coalescence (coagulation) of neighboring particles may also occur. However, it is worth keeping in mind that the coalescence of ordered precipitates often requires the formation of antiphase boundaries (APB's) that have a high energy cost in such systems. The $\mathrm{Co}_{3}(\mathrm{~W}, \mathrm{Al})$ $\mathrm{L}_{2} \gamma$ ' phase is indeed known to have a high critical temperature (high order energy). There are 4 ordering variants of the $\mathrm{L} 1_{2}$ ordered $\gamma$ ' phase. As a result, the probability to get two "out of phase particles" (OPPs) with an APB is $3 / 4$ and is $1 / 4$ for "in phase particles" (IPPs). Thus, coalescence of neighboring ordered $\gamma$ 'particles is difficult and rarely observed. This so-called discontinuous rafting microstructure has been observed in commercial Ni-based superalloys [35-40].

\section{Temporal evolution of phase composition}


As expected from the phase diagram, $\gamma^{\prime}$ precipitates are richer in $\mathrm{W}$ than the $\gamma$ matrix with a reconstructions related to ageing at $900^{\circ} \mathrm{C}$ for various times. $\gamma^{\prime}$ precipitates are delineated by 10 at. $\% \mathrm{~W}$ isoconcentration surfaces, a value that was chosen between the composition of the two phases. The generated proxigrams (i.e. proximity histograms) [41-42] for different $\gamma$ and $\gamma^{\prime}$ interfaces confirm that $\mathrm{W}$ has a very strong tendency to partition to the $\gamma^{\prime}$ phase, unlike $\mathrm{Al}$, in agreement with the phase diagram. The sum of $\mathrm{Al}$ and $\mathrm{W}$ contents in the $\gamma^{\prime}$ phase is close to 25 at. $\%$, corresponding to the the expected stoichiometry of the $\gamma^{\prime} \mathrm{Co}_{3}(\mathrm{Al}, \mathrm{W})$ ordered phase. This suggests that $\mathrm{Al}$ and $\mathrm{W}$ both occupy preferentially the corner sites of the same sub-lattice in the ordered $\mathrm{L} 1_{2}$ structure. The composition of both phases was determined away from $\gamma / \gamma^{\prime}$ interface, the standard deviation $\sigma$ can be written as [43] $\sigma=\left[C_{i}\left(1-C_{i}\right) / N\right]^{1 / 2}$ with $C_{\mathrm{i}}$ is the average concentration of element $\mathrm{i}$ and $\mathrm{N}$ the total number of atoms in the selected $\gamma^{\prime}$ precipitates (or in the $\gamma$ phase). Fig. $8 \mathrm{a}$ and $8 \mathrm{~b}$ show the temporal evolution of the $\mathrm{W}$ content in the $\gamma$ and $\gamma^{\prime}$ phases. As shown in Fig. 8, the $\mathrm{W}$ content in both phases evolves with ageing time. The $\mathrm{W}$ concentration decreases with time in both phases. Atomic fractions of $\mathrm{W}$ approach their equilibrium values according to Sato [1]: $5.60 \pm 0.02$ at.\% and $13.85 \pm 0.03$ at. $\%$ respectively in $\gamma$ and $\gamma^{\prime}$ after 100 hrs. Whereas the decrease of $\mathrm{W}$ content in $\gamma$ phase (decrease of supersaturation) is an expected behavior, that in precipitates is less common and deserves special attention. Such a behavior will be discussed in the next section, in view of the latest nucleation and growth-coarsening theories.

The significant decrease of the supersaturation in the parent phase observed from $5 \mathrm{~min}$ to 10 hrs strongly suggests that the pure growth stage continues up to ageing times close to $100 \mathrm{hrs}$, and has started in the first minutes of annealing. Let us remind that coarsening is the final stage of precipitation where the solute concentration in the parent phase evolve very slowly and is very close to its equilibrium value. This scenario is confirmed by the evolution of the 
volume fraction of $\gamma^{\prime}$ precipitates (Fig. 9, derived from the lever rule), which is found to significantly increase from $5 \mathrm{~min}$ to $10 \mathrm{hrs}$ (from $\sim 18 \%$ to $24 \%$ ) and more slowly during the coarsening stage. For longest ageing times $(100 \mathrm{hrs})$, the $\mathrm{W}$ content in the $\gamma$ matrix tends to an almost constant value, which is thought to be close to the solubility limit of $\mathrm{W}$ in the $\gamma$ phase at $900^{\circ} \mathrm{C}\left(5.4\right.$ at. \%), and the $\gamma^{\prime}$ volume fraction reached its equilibrium value ( $\left.25 \%\right)$. A more detailed interpretation of this evolution of the $\mathrm{W}$ content in both phases and of the overall kinetics is discussed below.

IV. KINETICS OF PRECIPITATION: experiments versus theories

\section{Nucleation and growth regimes}

It is clear from the experiments (Fig. 2b) that $\gamma^{\prime}$ precipitates nucleate during quenching. However, the volume fraction of $\gamma^{\prime}$ has not yet reached its equilibrium value even after 5 min at $900^{\circ} \mathrm{C}$. Due to the remaining supersaturation in the parent phase, nucleation might continue in the early stages of ageing. We shall examine this post-quench nucleation in more details in the following. In particular we will examine nucleation in the framework of recent theories dealing with multicomponent systems where ternary effects are expected [44].

In the limit of low supersaturation, the knowledge of only a few thermodynamic and kinetic parameters, specifically the Hessian of the Gibbs energy of the phases (i.e. the second derivative of the energy with respect to compositions $\left.\partial^{2} G / \partial C^{2}\right)$, the surface energy and the solute diffusivities, makes possible the determination of the properties of the new phase such as the size of the first nuclei and their composition [44], the driving force for nucleation and the nucleation rate [45].

In a recent theoretical work on nucleation in multicomponent systems, properties of the critical nucleus were derived using the capillarity theory in the framework of classical 
nucleation, and proposed an analytical solution for the composition of the critical nuclei. It was found that the deviation in nucleus composition from the equilibrium tie-line is due to the difference in the Hessian of the Gibbs energy of the phases and the magnitude of the deviation in composition from equilibrium is in the order of the supersaturation. In that context, it was shown than the radius of the critical nucleus can be written in a very general way as [44]:

$$
R^{*}=\frac{2 \sigma V_{m}^{\gamma^{\prime}}}{(\Delta \overline{\mathbf{C}})^{T} \mathbf{G}^{\gamma} \Delta \mathbf{C}^{0}}
$$

with $R^{*}$ the critical radius, $\sigma$ the interfacial energy and $V_{m}^{\gamma^{\prime}}$ the molar volume of the $\gamma^{\prime}$ phase. $\mathbf{G}^{\gamma}$ is the Hessian of the Gibbs energy of the $\gamma$ phase evaluated at the equilibrium composition $\bar{C}_{i}^{\gamma} . \Delta \overline{\mathbf{C}}=\bar{C}_{i}^{\gamma^{\prime}}-\bar{C}_{i}^{\gamma}$ for $\mathrm{i}=\mathrm{Al}, \mathrm{W}$ is the equilibrium tie-line vector for the chosen nominal composition of the alloy $C_{j}^{0}$, and $\Delta \mathbf{C}^{0}=C_{j}^{0}-\bar{C}_{j}^{\alpha}$ for $\mathrm{j}=\mathrm{Al}$, W represents the vector supersaturation. Note that $\Delta \mathbf{C}^{0}=\bar{\Phi} \Delta \overline{\mathbf{C}}$ where $\bar{\Phi}$ is the molar fraction of the new phase at equilibrium. The initial driving force for nucleation, can be shown to be written in dyadic notation in the limit of small supersaturation as [44]

$$
\Delta G_{m}=(\Delta \overline{\mathbf{C}})^{T} \mathbf{G}^{\gamma} \Delta \mathbf{C}^{0}
$$

and therefore Eq.1 gives the classical expression for the critical size of a nucleus.

The Hessian of the Gibbs energy of the $\gamma$ and $\gamma^{\prime}$ phases and the equilibrium composition of both phases have been computed from a recent thermodynamic database of the Co-Al-W system relying on the CALPHAD approach [46]. The nominal composition of the alloy as provided by EDS $\left(C_{A l}^{0}=9.3 a t . \%\right.$ and $\left.C_{W}^{0}=7.4 a t \%\right)$, being representative of the overall composition of the material, was taken as a reference in the following computations. Thermodynamic equilibrium (tangent plane of $\mathrm{G}\left(C_{\mathrm{Al}}, C_{\mathrm{W}}\right)$ for both $\gamma$ and $\gamma^{\prime}$ phases) leads to 
$\bar{C}_{A l}^{\gamma}=9.07$ at.$\%$ and $\bar{C}_{W}^{\gamma}=5.85$ at. $\%$ for the $\gamma$ phase and $\bar{C}_{A l}^{\gamma}=9.9$ at. $\%$ and $\bar{C}_{W}^{\gamma}=11.47$ at. $\%$ for the $\gamma^{\prime}$ phase. These values of the equilibrium compositions give a molar fraction $\bar{\Phi}$ of the $\gamma^{\prime}$ phase at equilibrium of $\sim 27 \%$, in good agreement with APT measurements. The thermodynamic calculations predict a low partitioning of $\mathrm{Al}$ between the two phases at equilibrium, this is confirmed by the experiments (Fig. 7). The molar volume of the $\gamma^{\prime}$ phase is taken as $6.8 \times 10^{-6} \mathrm{~m}^{3} / \mathrm{mol}$ and the Hessians of the Gibbs energy of both phases are computed from the thermodynamic database. From Eq.2, the initial driving force for nucleation is calculated as $\sim 264 \mathrm{~J} / \mathrm{mol}$, and this gives a critical nucleus size of $\sim 2.5 \mathrm{~nm}$ (computed from Eq.1 with the surface energy derived from the following analysis of the coarsening regime, $\sigma=48 \mathrm{~mJ} / \mathrm{m}^{2}$, see next section). The size of the precipitates after $5 \mathrm{~min}$ annealing is, according to Fig. 5a, far above the critical size, this reveals that, even if nucleation is still operating, growth largely prevails.

Determining the critical size allows for the computation of the nucleation barrier,

$\Delta G^{*}=\frac{4 \pi \sigma R^{* 2}}{3}$

At the beginning of the transformation, $\sigma=48 \mathrm{~mJ} / \mathrm{m}^{2}$ gives $\Delta G^{*} \approx 75 \mathrm{k} T$ (k is the Boltzmann constant $\left(\mathrm{J}^{-\mathrm{K}^{-1}}\right)$ and $\mathrm{T}$ is the temperature $\left.(\mathrm{K})\right)$. Decreasing the interfacial energy $\sigma$ by $30 \%$ reduces the nucleation barrier by a factor 3 (and gives $\mathrm{R}^{*} \sim 1.7 \mathrm{~nm}$ ). From the nucleation barrier, the steady state nucleation rate I, i.e. the number of new clusters that are formed per unit volume and time, can be derived as follows [45]:

$$
I=\sqrt{\frac{\left|H_{R}\right|}{2 \pi k T}} \beta_{R} f_{0}\left(R^{*}\right)
$$

where $H_{R}$ is the second derivative with respect to $R$ of the work of formation of a cluster of size $R$ evaluated at $R=R^{*}$, and was shown to be equal to $-8 \pi \sigma$ [46]. $f_{0}\left(R^{*}\right)$, the distribution 
function of heterophase at $R=R^{*}$, expressed in the $\{R\}$-space in the Fokker-Planck framework, is related to the distribution function in the more classical $\{\mathrm{n}\}$-space through [45],

$v f_{0}\left(R^{*}\right)=4 \pi R^{* 2} f_{0}\left(n^{*}\right)$

with $v$ the atomic volume in the $\gamma$ phase and $n^{*}$ the number of atoms in the critical cluster, $f_{0}\left(n^{*}\right)$ the number of nucleation sites times the Boltzmann probability,

$f_{0}\left(n^{*}\right)=(1 / v) \exp \left(-\Delta G^{*} / k T\right)$

$\beta_{R}$ is the diffusivity in the $\{\mathrm{R}\}$-space and can be written, for diffusion-controlled growth, as [45]:

$\beta_{R}=\frac{k T V_{m}^{\gamma^{\prime}}}{4 \pi R^{* 3} \psi}$

with

$\psi=(\Delta \overline{\mathrm{C}})^{T} \mathrm{G}^{\gamma} \mathrm{D}^{-1} \Delta \overline{\mathrm{C}}$

where $\mathrm{D}^{-1}$ is the inverse of the interdiffusion matrix, which is approximated as

$$
D^{-1}=\left(\begin{array}{cc}
0 & 0 \\
0 & 1 / D_{W}
\end{array}\right)
$$

as $\mathrm{W}$ is the slow diffuser in the alloy. $D_{W}$ is the interdiffusion coefficient of $\mathrm{W}$ in $\gamma$ and is evaluated at the equilibrium composition from diffusion-couple experiments [46-48] $\left(D_{W}\right.$ $\left.=2 \times 10^{-18} \mathrm{~m}^{2} / \mathrm{s}\right) . D_{W}$ is found three orders of magnitude lower than $D_{A l}$. It should be also noted that the dependence of $\beta_{R}$ with $R$ (Eq.7) differs from the more classical result for interface-limited growth [45]. Moreover, the product $\mathrm{G}^{\gamma} \mathrm{D}^{-1}$ can also be written as $\mathbf{M}^{-1}$, the inverse of the mobility matrix, which is here non-diagonal even if $\mathrm{D}^{-1}$ is diagonal. The number density of precipitates formed after 5 min of ageing $\left(N_{5 \min }\right)$ can be calculated from 
Eq.4, assuming that nucleation rapidly reaches a steady state, i.e. neglecting the incubation time, $\tau_{R}=-k T / H_{R} \beta_{R}$ [46], that is comprised between $4 \mathrm{~s}$ and $10 \mathrm{~s}$ for $\sigma$ between $33 \mathrm{~mJ} / \mathrm{m}^{2}$ and $48 \mathrm{~mJ} / \mathrm{m}^{2}$, for example. Also assuming a constant driving force during the first $5 \mathrm{~min}$ (no drastic change in supersaturation), leads to (for $\sigma \sim 33 \mathrm{~mJ} / \mathrm{m}^{2}$ ) $N_{5 \min } \sim 2.10^{22}$ clusters $/ \mathrm{m}^{3}$, in the same order of magnitude as the experimental number density $\sim 8.10^{22}$ clusters $/ \mathrm{m}^{3}$ (Fig. 5a and Fig. 10), but with a difference by a factor of 4 , which suggests that most precipitates are formed during the quench. For this value of the surface energy, the updated supersaturation at 5min (Fig. 5a) leads to a decrease of the nucleation rate by various orders of magnitude, indicating that nucleation no more operates after $5 \mathrm{~min}$. This is still true if the surface energy is lowered down to values inferior to $30 \mathrm{~mJ} / \mathrm{m}^{2}$. The highest value of $\sigma$ gives, even for the initial supersaturation, a very low nucleation rate, indicating no nucleation during the first minutes of ageing and that only growth of the precipitates formed during the quench dominates the phase transformation process. Indeed, the predicted nucleation rates calculated for the highest value of the surface energy $\left(\sigma=48 \mathrm{~mJ} / \mathrm{m}^{2}\right)$ suggests that without the presence of the precipitates formed during the quench, the phase transformation would be considerably slower, as compared to the present study. In both cases, the theory predicts that only growth, and then coarsening, operate after $5 \mathrm{~min}$.

The composition of the critical nucleus can be derived as $\Delta \mathbf{C}^{\gamma^{\prime}, *}=\mathrm{C}^{\gamma^{\prime, *}}-\overline{\mathbf{C}}^{\gamma^{\prime}}=\mathrm{G}^{\gamma^{\prime}-1} \mathrm{G}^{\gamma} \Delta \mathrm{C}^{0}$

assuming no difference between the molar volume of the two phases [45], leading to $\Delta C_{A l}^{\gamma^{\prime}, *}=0.3 a t \%$ and $\Delta C_{W}^{\gamma^{\prime}, *}=1.36 a t \%$. As compared to the bulk phase, the nuclei are richer in $\mathrm{Al}$ and $\mathrm{W}$, but the capillary effect is quite negligible for $\mathrm{Al}(+0.3$ at.\% $)$. This higher amount of $\mathrm{Al}$ and $\mathrm{W}$ in $\gamma^{\prime}$ in the early stages is in good agreement with APT analyses that reveal a decrease of the $\mathrm{W}$ content in $\gamma^{\prime}$ with ageing time. 


\section{Coarsening regime}

Microstructural changes due to the reduction of the overall interfacial energy and consequently of interphase surfaces typically occurring at the end of a first-order transformation are known as Ostwald ripening [49,50] or coarsening [17,18]. The total interfacial energy of the system decreases and the size scale of the coarsening phase increases. Dissolution of small precipitates concomitantly entails growth of large ones through a diffusive mass flow from shrinking to growing precipitates. Lifshitz and Slyozov [17] and Wagner [18] were the first to describe the coarsening process in a dilute binary alloy. In this case, the interfacial compositions are set by the Gibbs-Thompson equation that links these compositions to the curvature of the precipitate. In multicomponent alloys, local equilibrium alone is no longer sufficient to determine the compositions at the interface and mass balance conditions must be employed to describe the growth kinetics of the precipitates. This has been done by Kuehmann and Voorhees [24] to describe Ostwald ripening in a ternary alloy. Historically, extensions of coarsening theory for multicomponent systems were carried out by several authors [51-57]. More recently, a very general coarsening theory was developed by Philippe and Voorhees (PV) that accounts for the diffusion couplings and allows the composition of the precipitate to depart from equilibrium [25]. The PV analysis shows that the temporal exponents for the average particle radius, number density of particles, and both the precipitate and matrix compositions are identical within the binary limit. However, the amplitudes are different. Moreover, it was revealed that the vector representing the matrix supersaturations coincides with the equilibrium tie-line, but in most alloys, this is not the case for the second phase composition [25,45]. This is precisely what is observed in APT experiments (Fig. 8). We shall examine this in more details hereafter.

The mean radius $(\bar{R})$ of the precipitates follows the classical LSW law: 


$$
\bar{R}^{3}(t)=K_{R} t
$$

with $K_{R}$ a rate constant [25],

$$
K_{R}=\frac{8 V_{m}^{\gamma^{\prime}} \sigma}{9 \psi}
$$

where $\psi$ is given by equation (8). As experimentally shown, the $\gamma^{\prime}$ precipitates are cuboidal, the particle radius $\mathrm{R}$ is replaced by $d / 2$ with $\mathrm{d}$ the mean edge length of the cubic precipitate. Fig. 10b shows a plot of $\log (d / 2)$ against $\log (\mathrm{t})$ as determined experimentally from SEM and TEM micrographs, and a temporal exponent of approximately $1 / 3$ is observed, indicating that the coarsening regime dominates the phase transformation from the early stages. From this result the surface energy can be derived using Eq.11 and Eq.12 with $K_{R}=0.67 \mathrm{~nm}^{3} / \mathrm{s}$ (Fig. 10c). This leads to $\sigma=48 \mathrm{~mJ} / \mathrm{m}^{2}$, which is a reasonable value for a $\gamma / \gamma^{\prime}$ interface but much larger than that deduced from a previous coarsening study performed in Co-Al-W alloys [16], where $\sigma=19 \mathrm{~mJ} / \mathrm{m}^{2}$ at $900{ }^{\circ} \mathrm{C}$. A comparable value of the surface energy is found $(\sigma \sim 17$ $\mathrm{mJ} / \mathrm{m}^{2}$ ) if the interdiffusion coefficient of $\mathrm{W}$ is multiplied by a factor 2 , because the procedure is very sensitive to the kinetic coefficients (Eq.8 and Eq.12). However the main difference with the analysis performed by Meher et al. [16] is that the determination of the rate constant $K_{R}$ relies in their study on the LSW theory modified by Calderon et al. [20]. In our case, a more accurate description of the thermodynamics of the phases is employed with a full coupling to kinetics (Eq.8). Indeed, the coefficient $\psi$ in $K_{R}$ (Eq.8) that couples both kinetics and thermodynamics is given, in the modified LSW, by $\psi=R T\left(\bar{C}_{\gamma^{\prime}}-\bar{C}_{\gamma}\right)^{2} / D \bar{C}_{\gamma}\left(1-\bar{C}_{\gamma}\right)$ [20], and was used in [16] for the determination of the interfacial energy. Contrary to LSW [17], the expression derived in [20] is valid for concentrated alloys and simpler than the one we use in the present analysis (Eq.8), which was derived in [25]. However, it is found that, in 
the present case, the expression proposed in [20] for $\psi$ overestimates its actual value, as given by Eq.8, by a factor $~ 1.5$. Indeed, using this expression instead of Eq.8 for the determination of the interfacial energy leads to a value of $30 \mathrm{~mJ} / \mathrm{m}^{2}$ at $900^{\circ} \mathrm{C}$, which is closer to the energies obtained in [16], $19 \mathrm{~mJ} / \mathrm{m}^{2}$ at $800{ }^{\circ} \mathrm{C}$ and $10 \mathrm{~mJ} / \mathrm{m}^{2}$ at $900{ }^{\circ} \mathrm{C}$, but still relatively larger than the energies derived using the modified LSW [16,20]; which therefore might have been underestimated.

According to the PV theory [25], the number density of the precipitates evolves as:

$$
N_{V}=0.21 \frac{\bar{\Phi}}{K_{R}} t^{-1}
$$

The experimental number density $\mathrm{N}_{\mathrm{V}}$ of $\gamma^{\prime}$ particles was estimated from TEM micrographs (Fig. 5). Fig. 10a shows the temporal evolution of $N_{V}$, which is found to decrease as $\mathrm{t}^{-0.89}$, in good agreement with theory (Eq.13). The prefactor $0.21 \bar{\Phi} / K_{R}$ (Eq.11) is close to $8.10^{25} \mathrm{~s} / \mathrm{m}^{2}$ for a value of $K_{R}=0.67 \mathrm{~nm}^{3} / \mathrm{s}$, which is of same order of magnitude than the experimental value $\left(10^{25} \mathrm{~s} / \mathrm{m}^{2}\right.$ Fig. 10a), and thus shows a reasonable agreement, as growth and coarsening superimpose.

During coarsening, the supersaturation slightly decreases as [25]

$$
\mathbf{C}^{\gamma}(t)=\overline{\mathbf{C}}^{\gamma}+\mathbf{K}_{C}^{\gamma} t^{-\frac{1}{3}}
$$

with,

$$
\mathbf{K}_{C}^{\gamma}=\left(3 \sigma V_{m}^{\gamma^{\prime}}\right)^{\frac{2}{3}} \Delta \overline{\mathbf{C}} \frac{\psi^{\frac{1}{3}}}{(\Delta \overline{\mathbf{C}})^{T} \mathbf{G}^{\gamma} \Delta \overline{\mathbf{C}}}
$$

and the $\mathrm{W}$ concentration in the "average precipitate" is given by [25] 
with

$$
\mathbf{K}_{C}^{\gamma^{\prime}}=\left(3 \sigma V_{m}^{\gamma^{\prime}}\right)^{\frac{2}{3}} \psi^{\frac{1}{3}}\left\{\frac{\mathbf{G}^{\gamma^{\prime}-1} \mathbf{G}^{\gamma} \Delta \overline{\mathbf{C}}}{(\Delta \overline{\mathbf{C}})^{T} \mathbf{G}^{\gamma} \Delta \overline{\mathbf{C}}}\right\}
$$

Fig. 11a and $11 \mathrm{~b}$ show the temporal evolution of $\mathrm{W}$ content in both $\gamma$ and $\gamma^{\prime}$ phases, measured by APT, that is found to linearly evolve with $\mathrm{t}^{-1 / 3}$ as predicted for a pure coarsening regime. One should also notice that the extracted composition in $\mathrm{W}$ at equilibrium in the $\gamma$ phase (5.5 at. $\%$ for $\left.\mathrm{t}^{-1 / 3} \sim 0\right)$ is in good agreement with the calculated equilibrium composition (5.85 at.\%, see previous section), but is far off for the $\gamma^{\prime}$ phase (13.8 at.\% experimentally versus 11.47 at. $\%$ as given by the thermodynamic data). Nevertheless, the measured rate constants for $\mathrm{W}$ are equal to 0.085 at. $\% / \mathrm{s}^{1 / 3}$ for $\gamma$ and to 0.027 at. $\% / \mathrm{s}^{1 / 3}$ for $\gamma^{\prime}$ (Fig. 11). The agreement with experiments is good. The amount of $\mathrm{W}$ in $\gamma^{\prime}$ precipitates decreases with ageing time. The rate constants compare reasonably well with the predicted ones calculated from Eq.14-17 that are respectively equal for $\mathrm{W}$ to $\sim 0.044$ at. $\% / \mathrm{s}^{1 / 3}$ and $\sim 0.038$ at. $\% / \mathrm{s}^{1 / 3}$, especially as the $\mathrm{W}$ content in the matrix at early times not only reflects a pure coarsening regime but also a concomitant growth process.

As shown in this section, atom probe tomography experiments have revealed a significant decrease of the $\mathrm{W}$ content in the $\gamma^{\prime}$ particles during annealing. To our knowledge such clear evidence of a compositional change in particles during phase separation has not yet been observed in Co-Al-W alloys, and is commonly very hard to exhibit [58]. Comparing the experimental and theoretical rate constants for the temporal evolution of the mean size of the precipitates have allowed for the determination of the interfacial $\gamma / \gamma^{\prime}$ energy $\sigma$, in fully coupling thermodynamics (from the CALPHAD method [46]) and kinetics. This full coupling 
was shown in [25] to set the particles composition during the phase transformation, as given by Eq.14-17. Remarkably enough, the current description of both thermodynamic and kinetic parameters that is employed here, combined with the derived value of $\sigma$, allows for a good prediction of the $\mathrm{W}$ content decrease in $\gamma^{\prime}\left(0.038\right.$ at. $\left.\% / \mathrm{s}^{1 / 3}\right)$ as compared with experiments $\left(0.027\right.$ at. $\left.\% / \mathrm{s}^{1 / 3}\right)$, and therefore shows that the PV theory [25] captures reasonably well the physics of Ostwald ripening in multicomponent alloys [24,25,54-56].

\section{CONCLUSION}

The kinetics of precipitation in a low supersaturated Co-9.1Al-7W model Co based superalloy aged at $900^{\circ} \mathrm{C}$ was investigated. Electron microscopy was used to determine the microstructural evolution and the average size and number density of $\gamma^{\prime}$ precipitates. Atom probe tomography was employed to measure the composition of both $\gamma$ and $\gamma^{\prime}$ phases. Experiments were confronted to most recent nucleation and coarsening theories for multicomponent alloys.

The following conclusions can be drawn:

i. Ordered $\gamma^{\prime}$ precipitates are formed during quenching with a distinct composition with regard to the parent phase.

ii. After ageing, the measured composition of $\gamma^{\prime}$ precipitates indicated a $\mathrm{Co}_{3}(\mathrm{Al}, \mathrm{W})$ stoichiometry, suggesting that both $\mathrm{Al}$ and $\mathrm{W}$ occupy preferentially the corner sites of the same sub-lattice in the ordered $\mathrm{L1}_{2}$ structure, as expected.

iii. The supersaturation in $\mathrm{W}$ and $\mathrm{Al}$ still decreases significantly after quench. This means that nucleation and growth continue during the early stages of ageing at $900^{\circ} \mathrm{C}$. Concomitantly the $\gamma^{\prime}$ volume fraction increases up to $100 \mathrm{hrs}$ where almost pure coarsening is observed.

iv. Temporal exponents for the average particle size, number of particles per volume were found identical to those expected for binary alloys during the coarsening 


\section{References}

[1] J. Sato, T. Omori, K. Oikawa, I. Ohnuma, R. Kainuma, K. Ishida, Cobalt-Base High-Temperature Alloys, Science 312 (2006) 90-91.

[2] A. Suzuki, T. M. Pollock, High-temperature strength and deformation of $\gamma / \gamma^{\prime}$ two-phase Co-Al-W-base alloys Acta Materialia 56 (2008) 1288-1297.

[3] Y.-J Wang, C.-Y Wang, A comparison of the ideal strength between L12Co3(Al,W) and Ni3Al under tension and shear from first-principles calculations, Appl. Phys. Lett. 94 (2009) 261909.

[4] A. Bauer, S. Neumeier, F. Pyczak, R. F. Singer, M. Göken, Creep properties of different $\gamma^{\prime}$-strengthened Cobase superalloys, Materials Science and Engineering A 550 (2012) 333-341.

[5] F. Pyczak, A. Bauer, M. Göken, S. Neumeier, U. Lorenz, M. Oehring, N. Schell, A. Schreyer, A. Stark, F. Symanzik, Plastic deformation mechanisms in a crept L12 hardened Co-base superalloy, Materials Science and Engineering A 571 (2013) 13-18.

[6] L. Shi, J. J. Yu, C. Y. Cui, X. F. Sun, The creep deformation behavior of a single-crystal Co-Al-W-base superalloy at $900{ }^{\circ} \mathrm{C}$, Materials Science and Engineering A 635 (2015) 50-58. 
[7] S. Kobayashi, Y. Tsukamoto, T. Takasugi, H. Chinen, T. Omori, K. Ishida, S. Zaefferer, Determination of phase equilibria in the Co-rich Co-Al-W ternary system with a diffusion-couple technique, Intermetallics 17 (2009) 1085-1089.

[8] Y. Tsukamoto, S. Kobayashi, T. Takasugi, The Stability of $\gamma$ '-Co3(Al,W) Phase in Co-Al-W Ternary SystemMaterials, Science Forum 654-656 (2010) 448-451.

[9] T. Omori, K. Oikawa, J. Sato, I. Ohnuma, U.R. kattner, R. Kainuma, K. Ishida, Partition behavior of alloying elements and phase transformation temperatures in Co-Al-W-base quaternary systems, Intermetallics 32 (2013) 274-283.

[10] E. A. Lass, M. E.Williams, C. E. Campbell, K. W. Moon, U. R. Kattner, $\gamma^{\prime}$ Phase Stability and Phase Equilibrium in Ternary Co-Al-W at $900{ }^{\circ} \mathrm{C}$, J. Phase Equilib. Diffus. 35 (2014) 711-723.

[11] P.J. Bocchini, E. A. Lass, K. -W. Moon, M. E. Williams, C.E. Campbell, U.R. Kattner, D.C. Dunand, D.N. Seidman, Atom-probe tomographic study of $\gamma / \gamma^{\prime}$ interfaces and compositions in an aged Co-Al-W superalloy, Scripta Materialia 68 (2013) 563-566.

[12] S. Meher, R. Banerjee, Partitioning and site occupancy of Ta and Mo in Co-base $\gamma / \gamma^{\prime}$ alloys studied by atom probe tomography, Intermetallics 49 (2014) 138-142.

[13] S. Meher, H. Y. Yan, S. Nag, D. Dye, R. Banerjee, Solute partitioning and site preference in $\gamma / \gamma^{\prime}$ cobalt-base alloys, Scripta Materialia 67 (2012) 850-853.

[14] I. Povstugar, P. -P. Choi, S. Neumeier, A. Bauer, C. H. Zenk, M. Göken, D. Raabe, Elemental partitioning and mechanical properties of $\mathrm{Ti}$ - and Ta-containing $\mathrm{Co}-\mathrm{Al}-\mathrm{W}$-base superalloys studied by atom probe tomography and nanoindentation, Acta Materialia 78 (2014) 78.

[15] F. Pyczak, A. Bauer, M. Göken, U. Lorenz, S. Neumeier, M. Oehring, J. Paul, N. Schell, A. Schreyer, A. Stark, F. Symanzik, The effect of tungsten content on the properties of L12-hardened Co-Al-W alloys. Journal of Alloys and Compounds, Journal of Alloys and Compounds 632 (2015) 110-115.

[16] S. Meher, S. Nag, J. Tiley, A. Goel, R. Banerjee, Coarsening kinetics of $\gamma^{\prime}$ precipitates in cobalt-base alloys, Acta Materialia 61 (2013) 4266-4276.

[17] I.M. Lifshitz, V.V. Slyozov, The kinetics of precipitation from supersaturated solid solutions, Journal of Physics and Chemistry of Solids 19 (1961) 35-50.

[18] C.Wagner, Theorie der Alterung von Niderschlagen durch Umlösen (Ostwald Reifung), Z.Electrochem 65 (1961) 581-591.

[19] D. McLean, Predicting growth of $\gamma^{\prime}$ in nickel alloys, Metal Science 18 (1984) 249-256.

[20] H.A. Calderon, P. W. Voorhees, J. L. Murray, G. Kostorz, Ostwald ripening in concentrated alloys Acta Metallurgica et Materialia 42 (1994) 991-1000.

[21] C. Schmuck, P. Caron, A. Hauet, D. Blavette, Ordering and precipitation of $\gamma^{\prime}$ phase in low supersaturated NiCr-Al model alloy: An atomic scale investigation, Phil Mag A 76 (1997) 527-542.

[22] D.J. Sauza, P. J. Bocchini, D. C. Dunand, D. N. Seidman, Influence of ruthenium on microstructural evolution in a model CoAlW superalloy, Acta Materialia 117 (2016) 135, 135-145.

[23] V.A. Vorontsov, J.S. Barnard, K.M. Rahman, H.-Y. Yan, P.A. Midgley, D. Dye, Coarsening behaviour and interfacial structure of $\gamma^{\prime}$ precipitates in Co-Al-W based superalloys, Acta Materialia 120 (2016) 14-23.

[24] C.J. Kuehmann, P.W. Voorhees, Ostwald ripening in ternary alloys, Metallurgical and Materials Transactions A 27 (1996) 937-943.

[25] T. Philippe, P.W. Voorhees, Ostwald ripening in multicomponent alloys, Acta Materialia 61 (2013) 42374244. 
[26] B. Gault, F. Vurpillot, A. Vella, M. Gilbert, A. Menand, D. Blavette, B. Deconihout, Design of a Femtosecond Laser Assisted Tomographic Atom Probe, Review of Scientific Instruments 77 (2006) 043705.

[27] D. J. Larson, D. T. Foord, A. K. Petford-Long, H. Liew, M. G. Blamire, A. Cerezo, G. D. W. Smith, Field-ion specimen preparation using focused ion-beam milling, Ultramicroscopy 79 (1999) 287-293.

[28] G. B. Thompson, M. K. Miller, H. L. Fraser, Some aspects of atom probe specimen preparation and analysis of thin film materials, Ultramicroscopy 100 (2004) 25-34.

[29] M.K. Miller, K.F. Russell, G.B. Thompson, Strategies for fabricating atom probe specimens with a dual beam FIB, Ultramicroscopy 102 (2005) 287.

[30]M.K. Miller, G.D.W. Smith, Atom Probe Microanalysis: Principles and Applications to Materials Problems, Pittsburgh, PA, 1989

[31] W.A. Soffa, D. E. Laughlin, Decomposition and ordering processes involving thermodynamically first-order order $\rightarrow$ disorder transformations, Acta Metallurgica 37 (1989) 3019-3028.

[32] D. Blavette, A. Bostel, J. M. Sarrau, Atom-probe microanalysis of a nickel-base superalloy, MTA 16 (1985) 1703-1711.

[33] F. Danoix, G. Grancher, A. Bostel, D. Blavette, Standard deviations of composition measurements in atom probe analyses-Part II: 3D atom probe Ultramicroscopy, 107 (2007) 739-743.

[34] H. Yamauchi, D. De Fontaine, Elastic interaction of defect clusters with arbitrary strain fields in an anisotropic continuum, Acta Metallurgica 27 (1979) 763-776.

[35] T. Miyazaki, H. Imamura, H. Mori, T. Kozakal, Theoretical and experimental investigations on elastic interactions between $\gamma^{\prime}$-precipitates in a Ni-Al alloy, J Mater Sci 16 (1981) 1197-1203.

[36] M. Doi, T. Miyazaki, $\gamma^{\prime}$ Precipitate morphology formed under the influence of elastic interaction energies in nickel-base alloys, Materials Science and Engineering 78 (1986) 87-94.

[37] A. D. Sequeira, H. A. Calderon, G. Kostorz, Shape and growth anomalies of $\gamma^{\prime}$ precipitates in Ni-Al-Mo alloys induced by elastic interaction, Scripta Metallurgica et Materialia 30 (1994) 7-12.

[38] Y. Wang, D. Banerjee, C. C. Su, A. G. Khachaturyan, Field kinetic model and computer simulation of precipitation of L12 ordered intermetallics from f.c.c. solid solution, Acta Materialia 46 (1998) 2983-3001.

[39] V. Vaithyanathan, L. Q. Chen, Coarsening of ordered intermetallic precipitates with coherency stress, Acta Materialia 50 (2002) 4061-4073.

[40] Y. Tsukada, Y. Murata, T. Koyama, M. Morinaga, Phase-Field Simulation of the Effect of Elastic Inhomogeneity on Microstructure Evolution in Ni-Based Superalloys, Materials Transactions 50 (2009) 744-748.

[41] M.K. Miller, Interface analysis with the three-dimensional atom probe, Surf. Interface Anal. 31 (2001) 593598 .

[42] K.E. Yoon, R. D. Noebe, O. C. Hellman, D. N. Seidman, Dependence of interfacial excess on the threshold value of the isoconcentration surface, Surf. Interface Anal. 36 (2004) 594-597.

[43] F. Danoix, G. Grancher, A. Bostel, D. Blavette, Standard deviations of composition measurements in atom probe analyses. Part I, Ultramicroscopy 107 (2007) 734-738. 
[44] T. Philippe, D. Blavette , P. W. Voorhees, Critical nucleus composition in a multicomponent system, The Journal of Chemical Physics 141 (2014) 124306.

[45] T. Philippe, M. Bonvalet, D. Blavette, Kinetic theory of diffusion-limited nucleation, The Journal of Chemical Physics 144 (2016) 204501.

[46] Y.F. Cui, X. Zhang, G.L. Xu, W.J. Zhu, H.S. Liu, Z.P. Jin, Thermodynamic assessment of Co-Al-W system and solidification of Co-enriched ternary alloys, J Mater Sci 46 (2011) 2611-2621.

[47] R. Ravi, A. Paul, Interdiffusion study on $\mathrm{Co}(\mathrm{W})$ solid solution and topological close-packed $\mu$ phase in Co-W system, Intermetallics 19 (2011) 426-428.

[48] Y.-W. Cui, G. Xu, R. Kato, X.-G Lu, R. Kainuma, K. Ishida, Interdiffusion and Atomic Mobility for FaceCentered Cubic (FCC) Co-W Alloys, Metall and Mat Trans A 44 (2013) 1621-1625.

[49] W. Ostwald, Blocking of Ostwald ripening allowing long-term stabilization, Z. phys. Chem. 37 (1901) $385-$ 390.

[50] W. Ostwald, Analytisch Chemie, 3rd ed., Englemann, Leipzig, 1901.

[51] S. Björklund, L.F. Donaghey, M. Hillert, The effect of alloying elements on the rate of ostwald ripening of cementite in steel, Acta Metallurgica 20 (1972) 867-874.

[52] V.V. Slezov and V.V. Sagalovich, Theory of diffusive decomposition of supersaturated multicomponent systems, J. Phys. Chem. Solids, 38 (1977) 943-948.

[53] V.V. Slezov, V.V. Sagalovich, Diffusive decomposition of solid solutions, Sov. Phys. Usp. 30 (1987) 2345.

[54] A. Umantsev, G.B. Olson, Ostwald ripening in multicomponent alloys, Scripta Metallurgica et Materialia 29 (1993) 1135-1140.

[55] J.E. Morral and G.R. Purdy, Particle coarsening in binary and multicomponent alloys, Scripta Metallurgica et Materialia 30 (1994) 905-908.

[56] J.J. Hoyt, Coarsening in multiphase multicomponent systems-I, Acta Materialia 47 (1998) 345-351.

[57] J.A. Marqusee, J. Ross, Kinetics of phase transitions: Theory of Ostwald ripening, The Journal of Chemical Physics 79 (1983) 373-378.

[58] Z. Mao, C. Booth-Morrison, C. K. Sudbrack, G. Martin, D. Seidman, Kinetic pathways for phase separation: An atomic-scale study in Ni-Al-Cr alloys, Acta Materialia 60 (2012) 1871-1888.

[59] M. Bonvalet, T. Philippe, X. Sauvage, D. Blavette, Modeling of precipitation kinetics in multicomponent systems: Application to model superalloys, Acta Materialia 100 (2015) 169-177

\section{Figures}

Fig. 1. APT mass spectrum of Co-9Al-7W in the as-quenched state.

Fig. 2. (a) Electron diffraction pattern along the [001] zone axis, (b) Dark field TEM micrograph taken from (100) spot micrograph of Co-9.1 Al-7W (at.\%) alloy at quenched state. 
Fig. 3. As-quenched state. (a), (b) and (c) are cross-sections of APT 3D reconstructed volume showing the distribution of $\mathrm{Co}, \mathrm{Al}$ and $\mathrm{W}$ respectively. (d) Composition and apparent atomic density profiles along the tip axis, showing the low apparent atomic density in high evaporation field W-enriched $\gamma$ ' regions due to defocusing effects (local magnification effects).

Fig. 4. Backscattered SEM micrograph showing the heterogeneous precipitation of $\mathrm{Co}_{3} \mathrm{~W}$ at grain boundaries after annealing at $900{ }^{\circ} \mathrm{C}$ for $100 \mathrm{hr}$ (the contrast arises from local chemistry).

Fig. 5. TEM micrographs showing the temporal evolution of the $\gamma-\gamma^{\prime}$ microstructure in Co-9.1Al-7W at $900{ }^{\circ} \mathrm{C}$ : (a) $5 \mathrm{~min}$, (b) $15 \mathrm{~min}$, (c) $1 \mathrm{hr}$ and (d)10 hr. (a,b,c) are dark field TEM micrographs taken from superlattice $\mathrm{L1}_{2}$ spots (a) [110] zone axis (b) and (c) [100] (d) bright field micrograph in the [100] zone axis.

Fig. 6. Backscattered SEM micrographs showing the temporal evolution of the $\gamma-\gamma^{\prime}$ microstructure in Co-9.1 Al-7W at $900{ }^{\circ} \mathrm{C}$ : (a) $100 \mathrm{hr}$ and (b) $200 \mathrm{hr}$.

Fig. 7. (a) APT three dimensional reconstructions related to $\mathrm{Co}-9 \mathrm{Al}-7 \mathrm{~W}$ (at.\%) alloys aged at $900{ }^{\circ} \mathrm{C}$ for different ageing times (5 min-100 hr), showing $\gamma^{\prime}$ precipitates delineated with a 10 at.\% $\mathrm{W}$ isosurface and the related proxigrams through $\gamma / \gamma^{\prime}$ interfaces.

Fig. 8. Temporal evolution of $\mathrm{W}$ content (a) in $\gamma$ phase, (b) in $\gamma^{\prime}$ as measured by APT.

Fig. 9. (a) Temporal evolution of the molar fraction ( volume fraction) of $\gamma^{\prime}$ phase as derived from the phase composition using the lever rule.

Fig. 10. Temporal evolution of microstructural features as derived from TEM and SEM observations. (a) The number density of precipitates $\mathrm{N}_{\mathrm{v}}$ versus time (b) $\log (\mathrm{d} / 2)$ vs. $\log (\mathrm{t})$ where $\mathrm{d}$ is the size of precipitates. (c) $(d / 2)^{3}$ against time. Black dots are data derived from TEM micrographs and red dots are date derived from SEM micrographs.

Fig. 11. Temporal evolution of the $\mathrm{W}$ content in (a) $\gamma$ parent phase and (b) $\gamma^{\prime}$ phase as derived from APT experiments. The dashed line is an eye guide showing linearity.

Table 1. The overall composition of as-quenched CoAlW as measured by APT for different base sample temperatures.

\begin{tabular}{llll} 
Tips & Temperature $(\mathrm{K})$ & $\mathrm{Al}($ at.\%) & $\mathrm{W}($ at.\%) \\
\hline 1 & 80 & 10.22 & 7.85 \\
\hline 2 & 80 & 10.16 & 7.89 \\
\hline 3 & 40 & 10.03 & 7.78 \\
\hline 4 & 40 & 10.30 & 8.04 \\
\hline 5 & 20 & 10.11 & 7.88 \\
\hline Average & & $\mathbf{1 0 . 1 6 \pm 0 . 0 9}$ & $\mathbf{7 . 8 8 \pm 0 . 1 0}$
\end{tabular}


Click here to download high resolution image

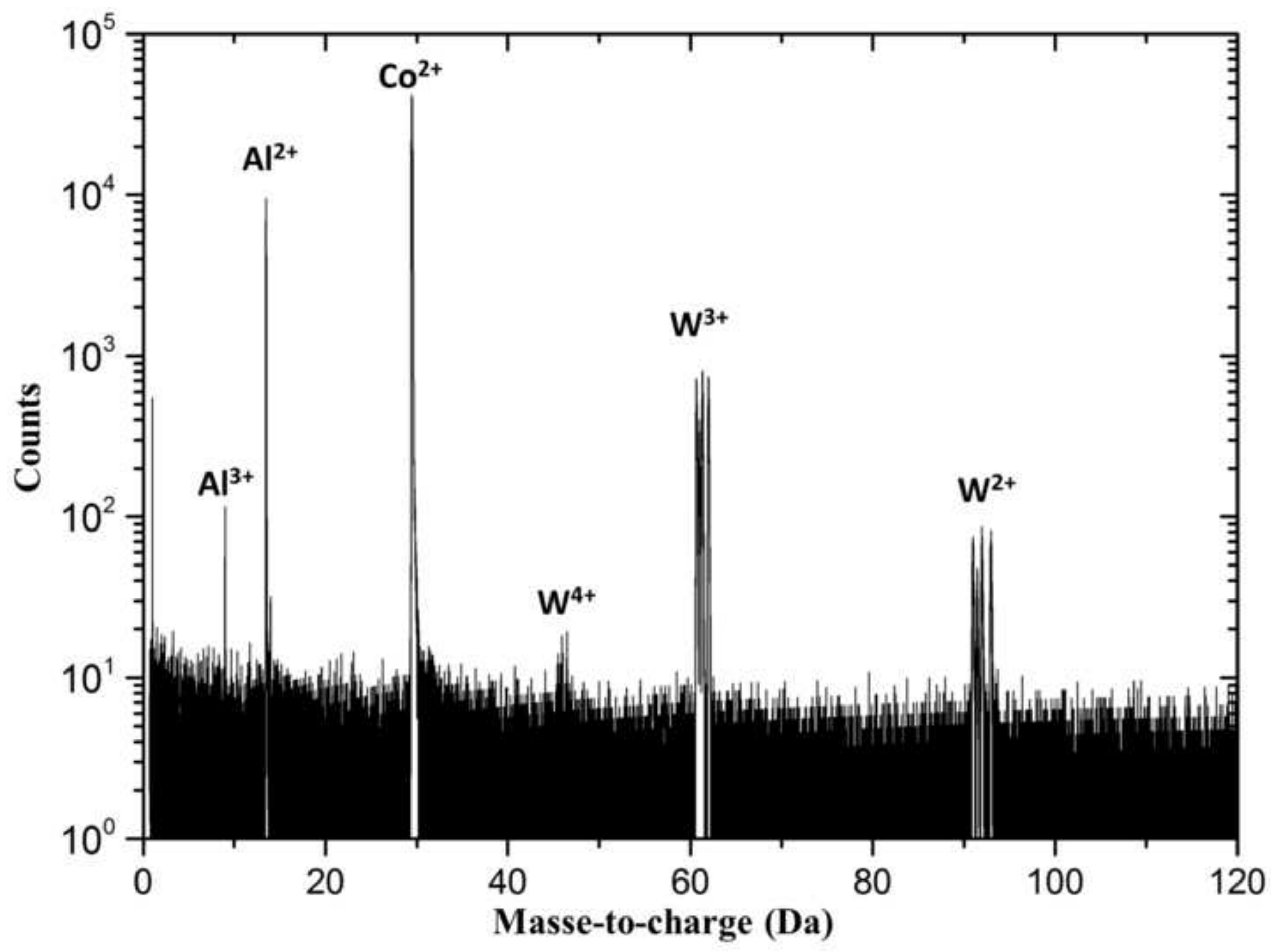




\section{Figure(s)}

Click here to download high resolution image
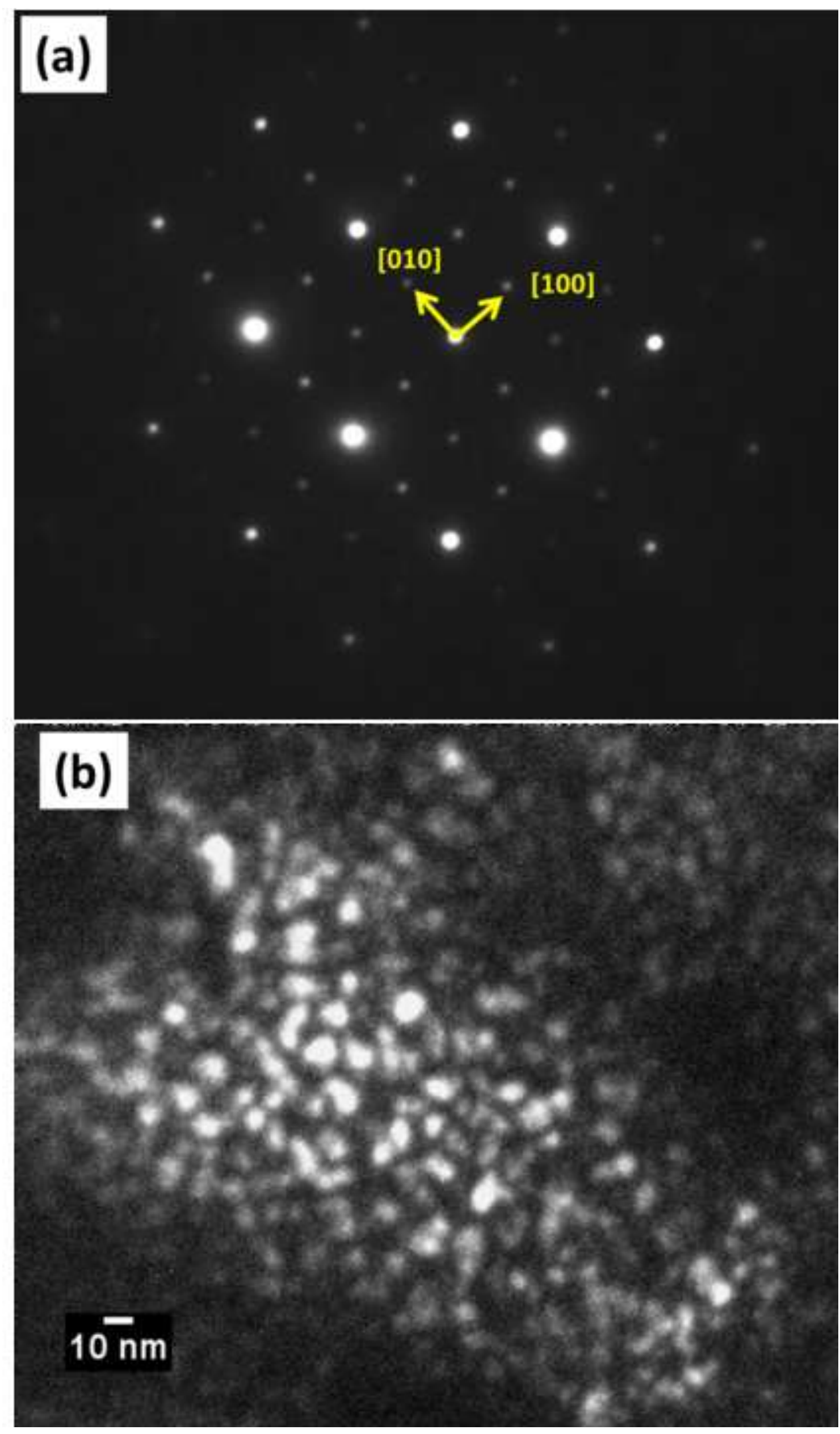

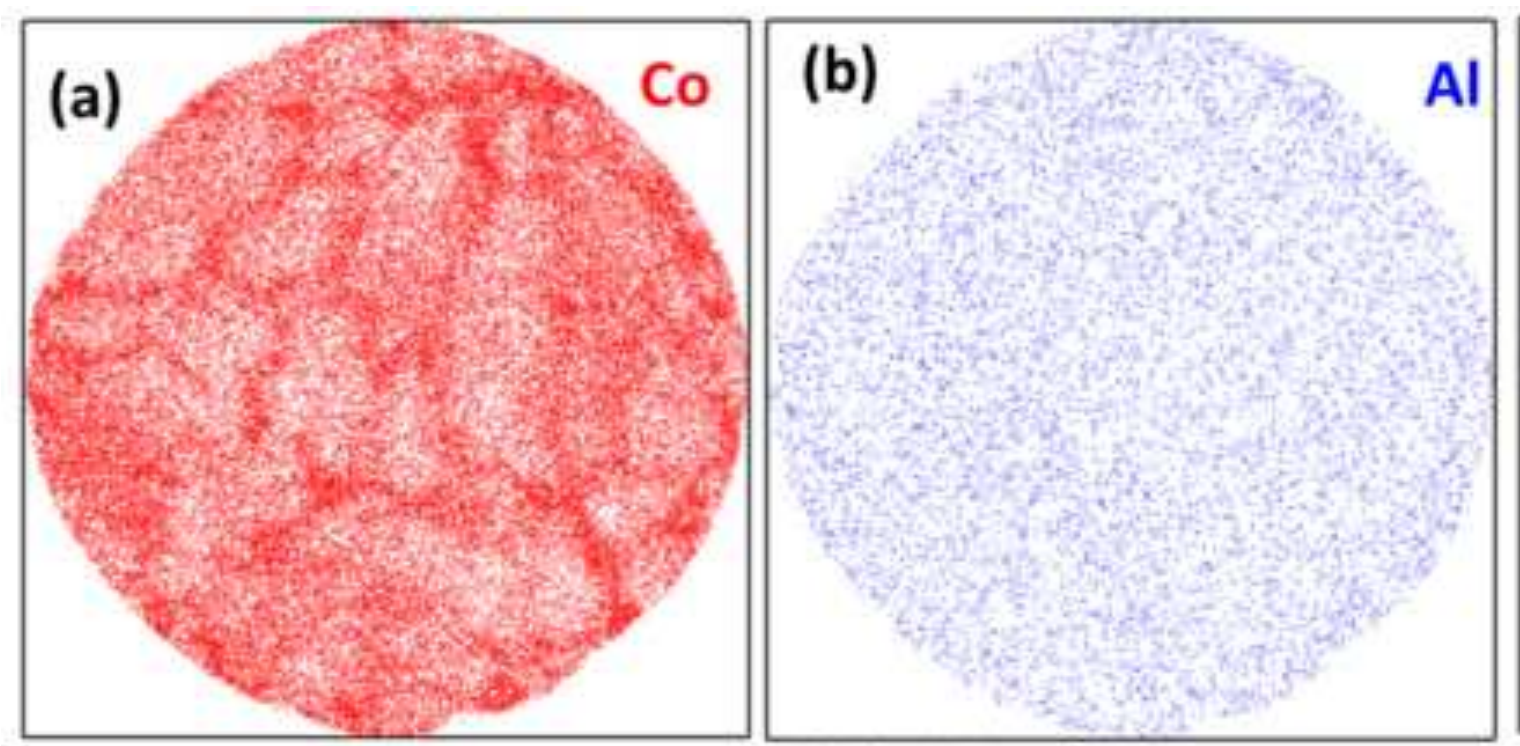

(c)

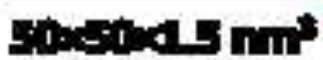

50mend.5 mon

Sowsom. $5 \mathrm{~mm}$

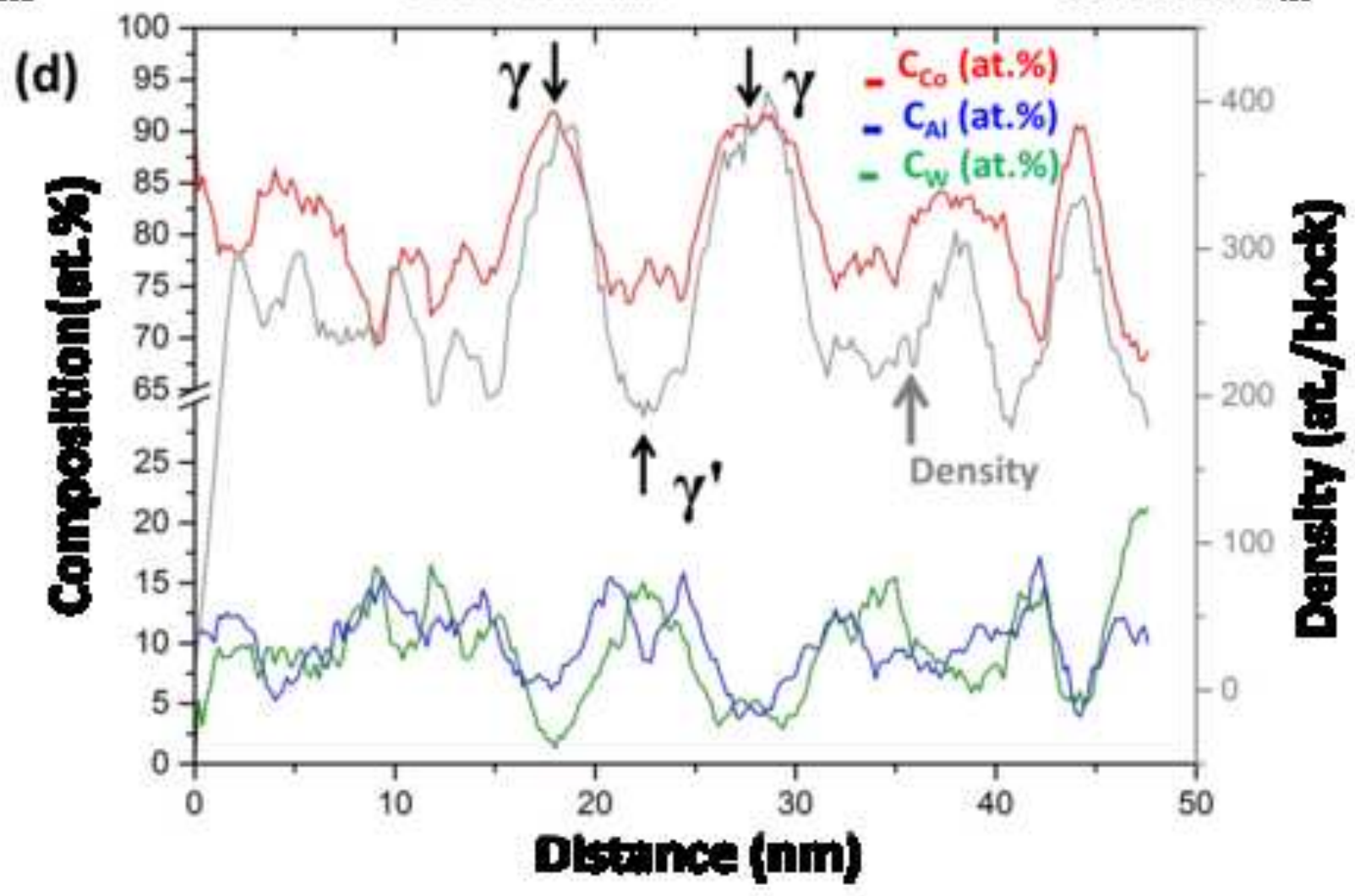


Figure(s)
Click here to download high resolution imag

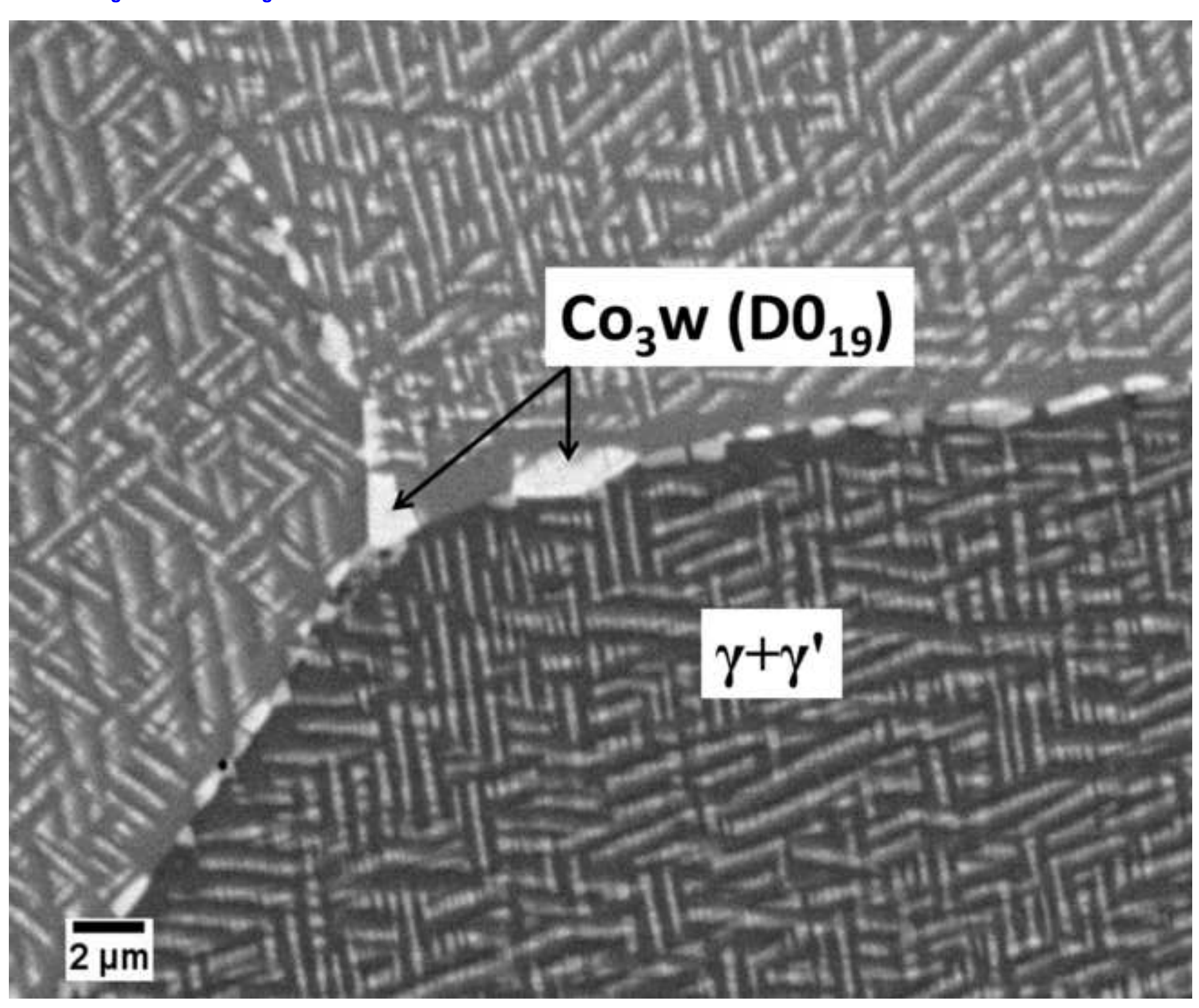

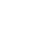
(1) . 


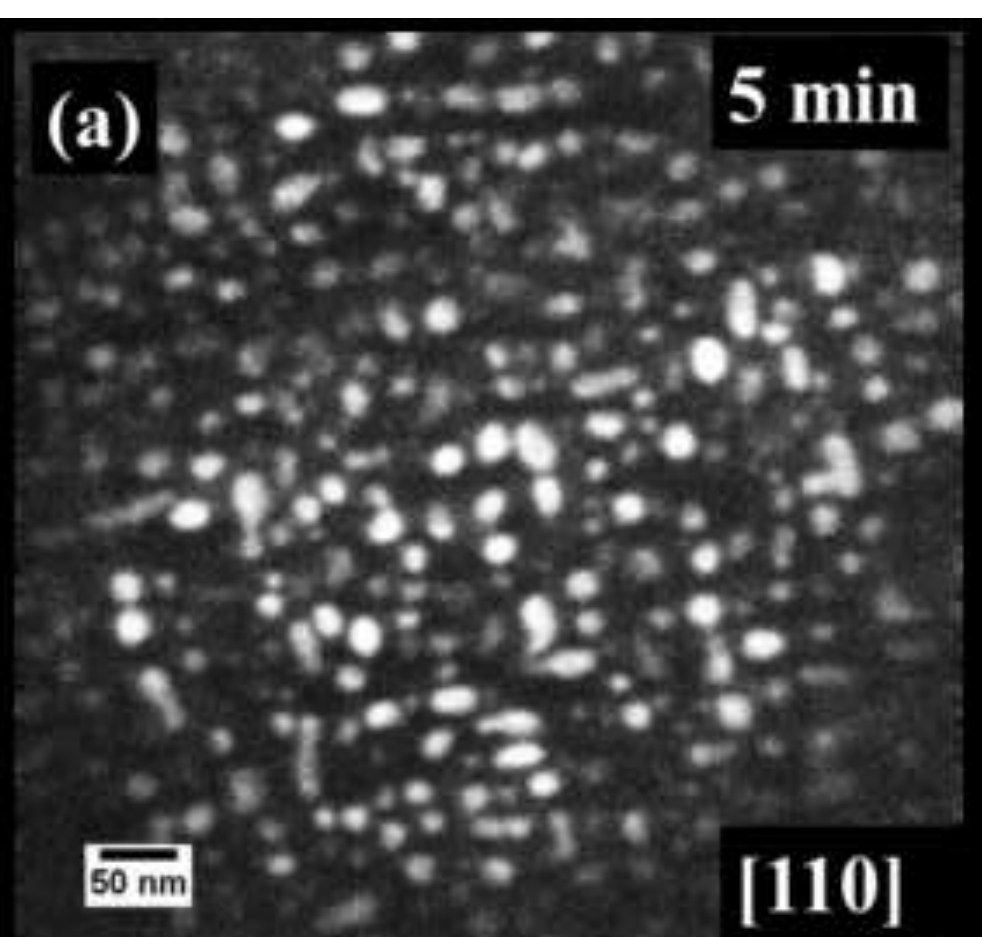

(b)

$15 \mathrm{~min}$
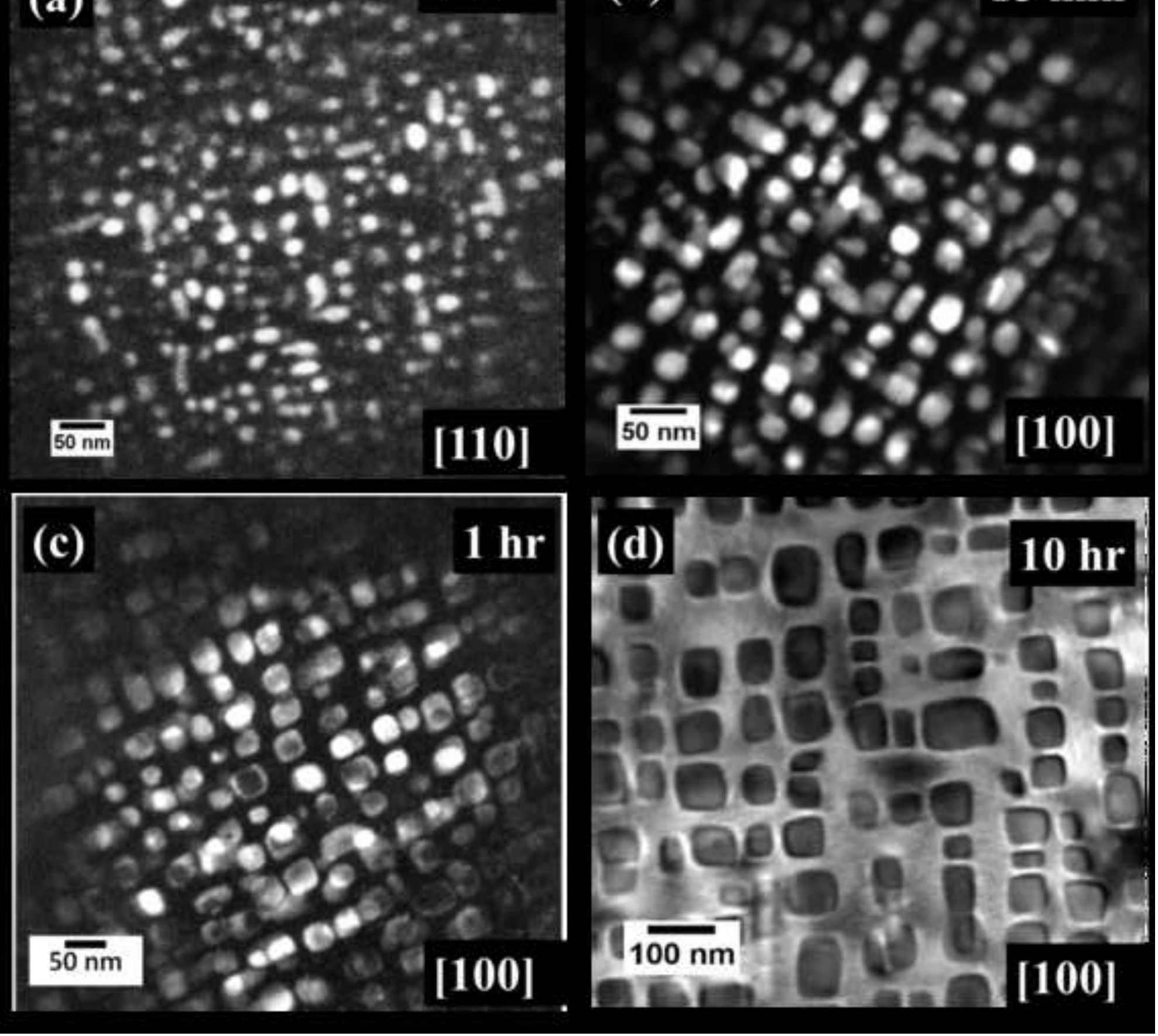
Click here to download high resolution image

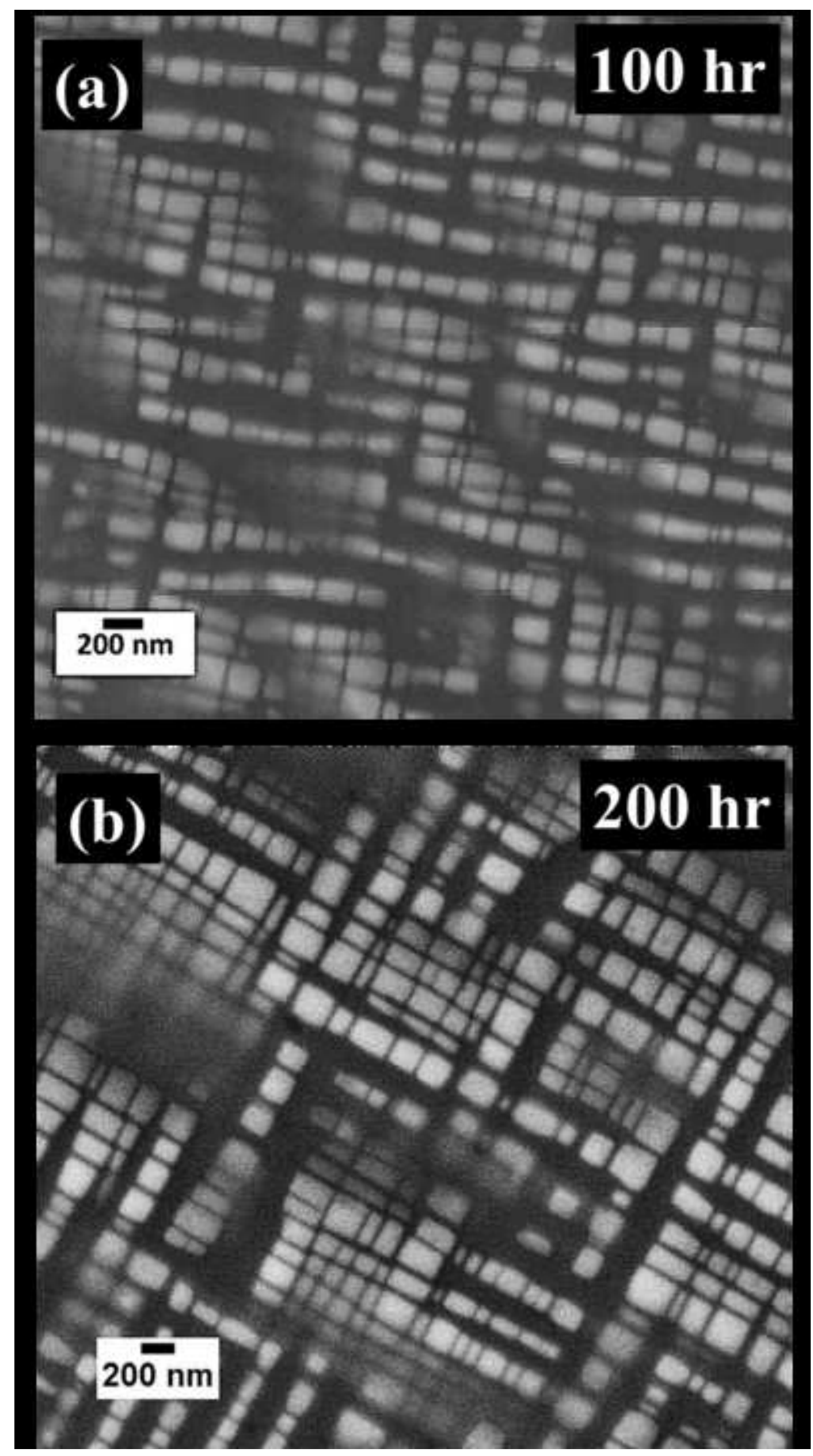



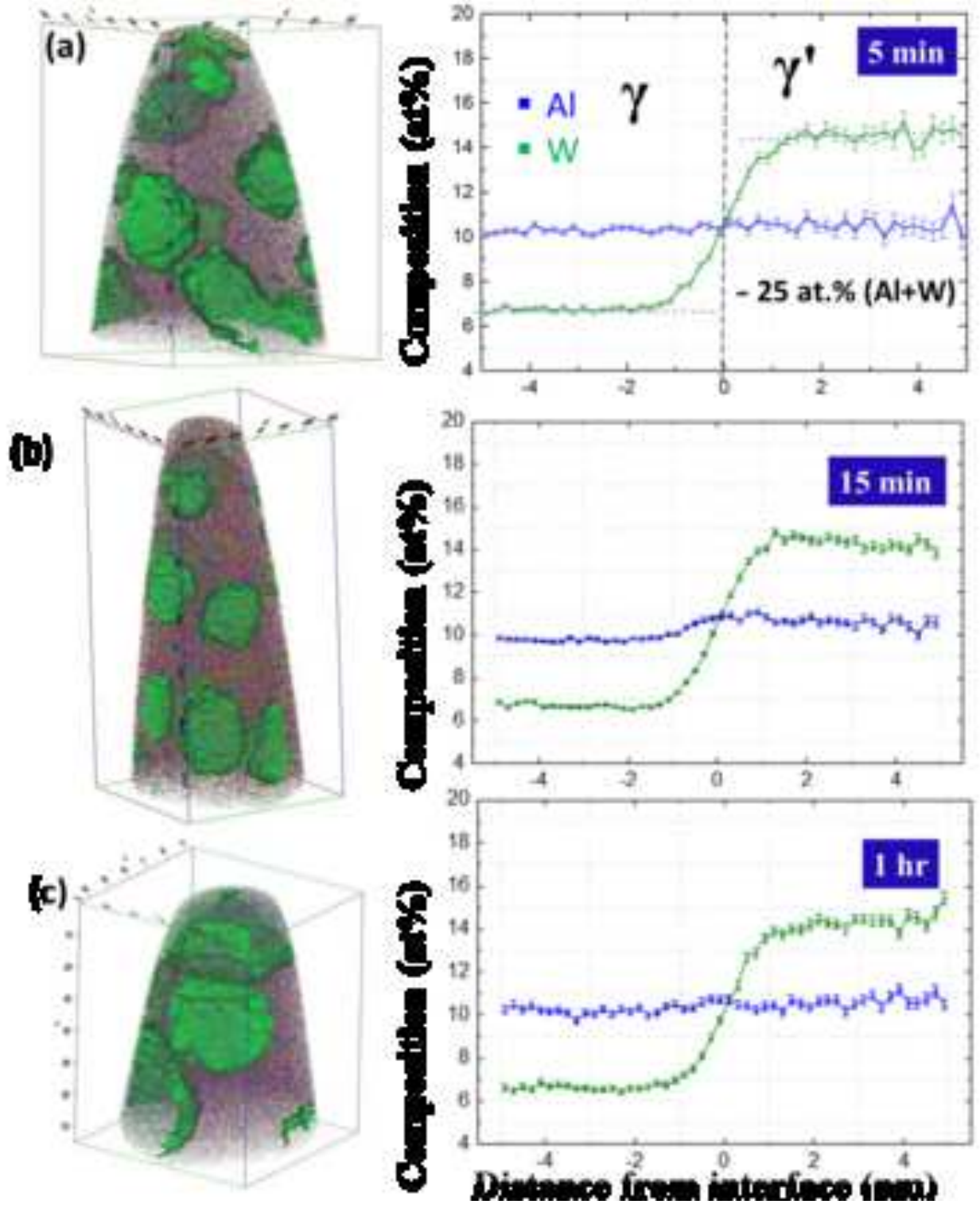
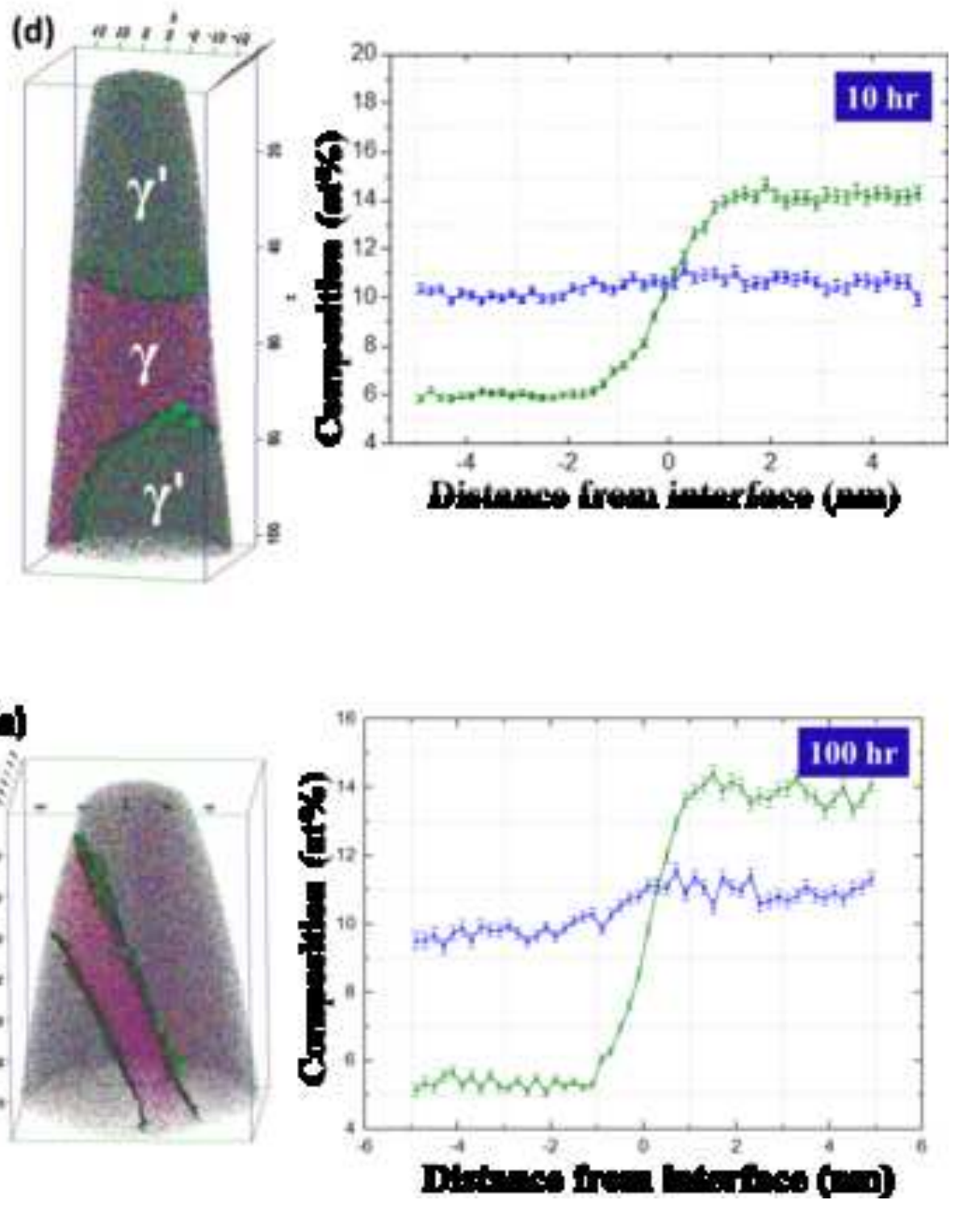

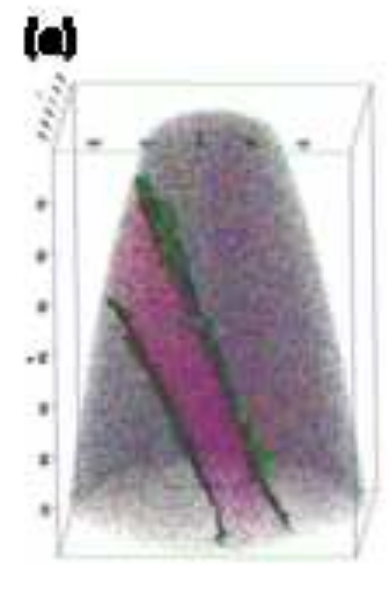

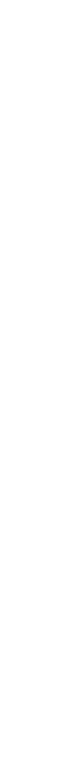


Click here to download high resolution image
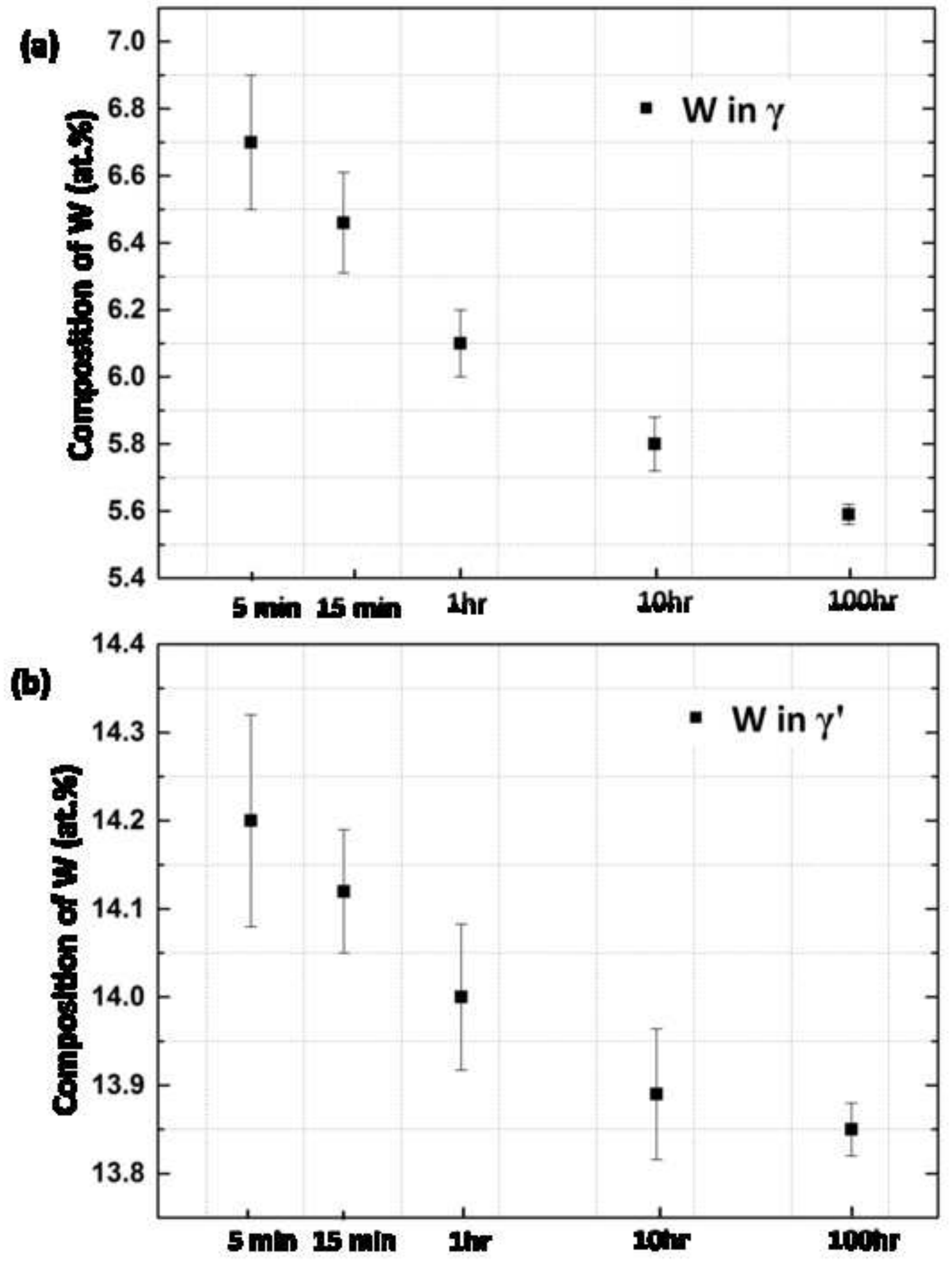
Figure(s)
Click here to download high resolution image

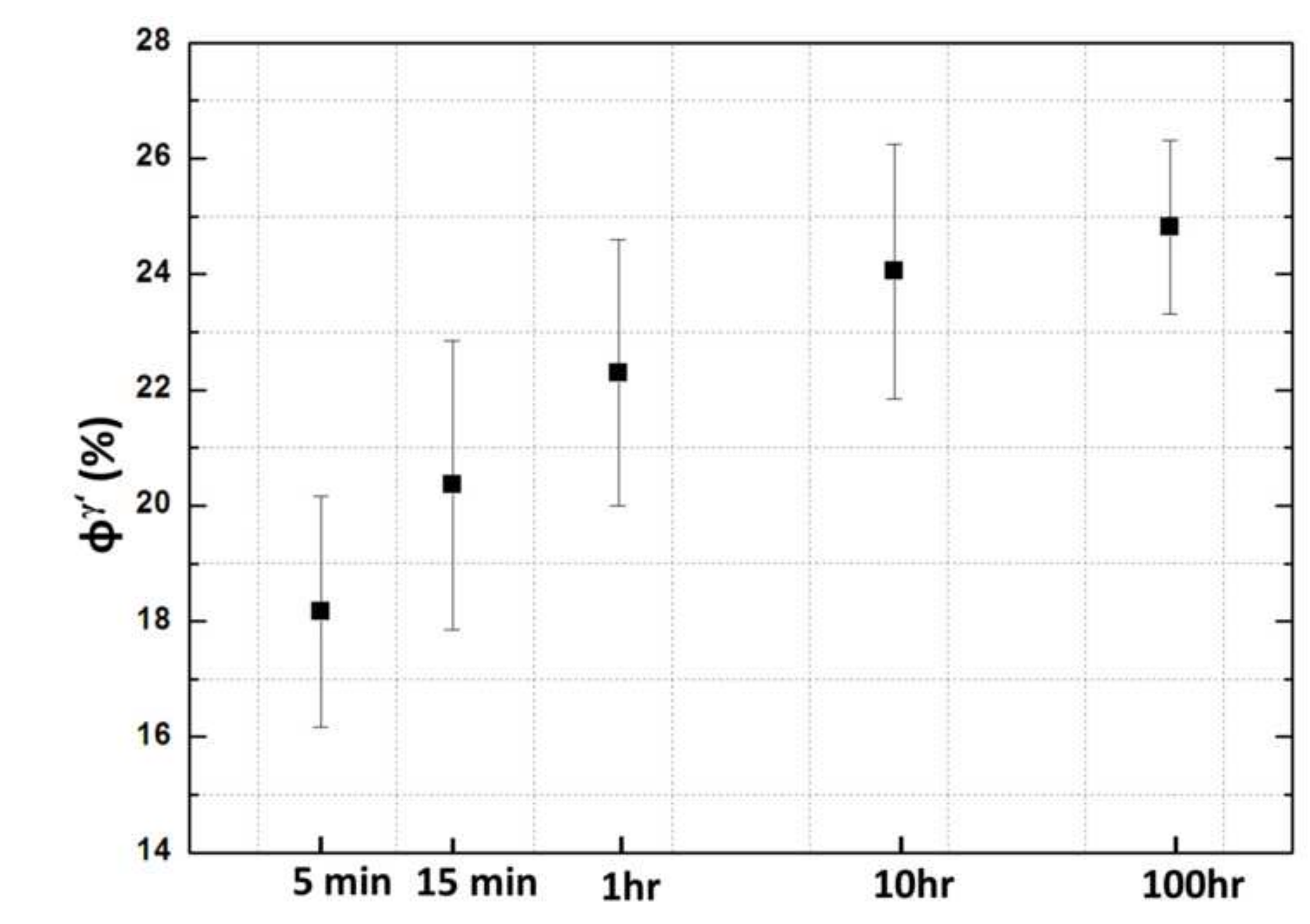



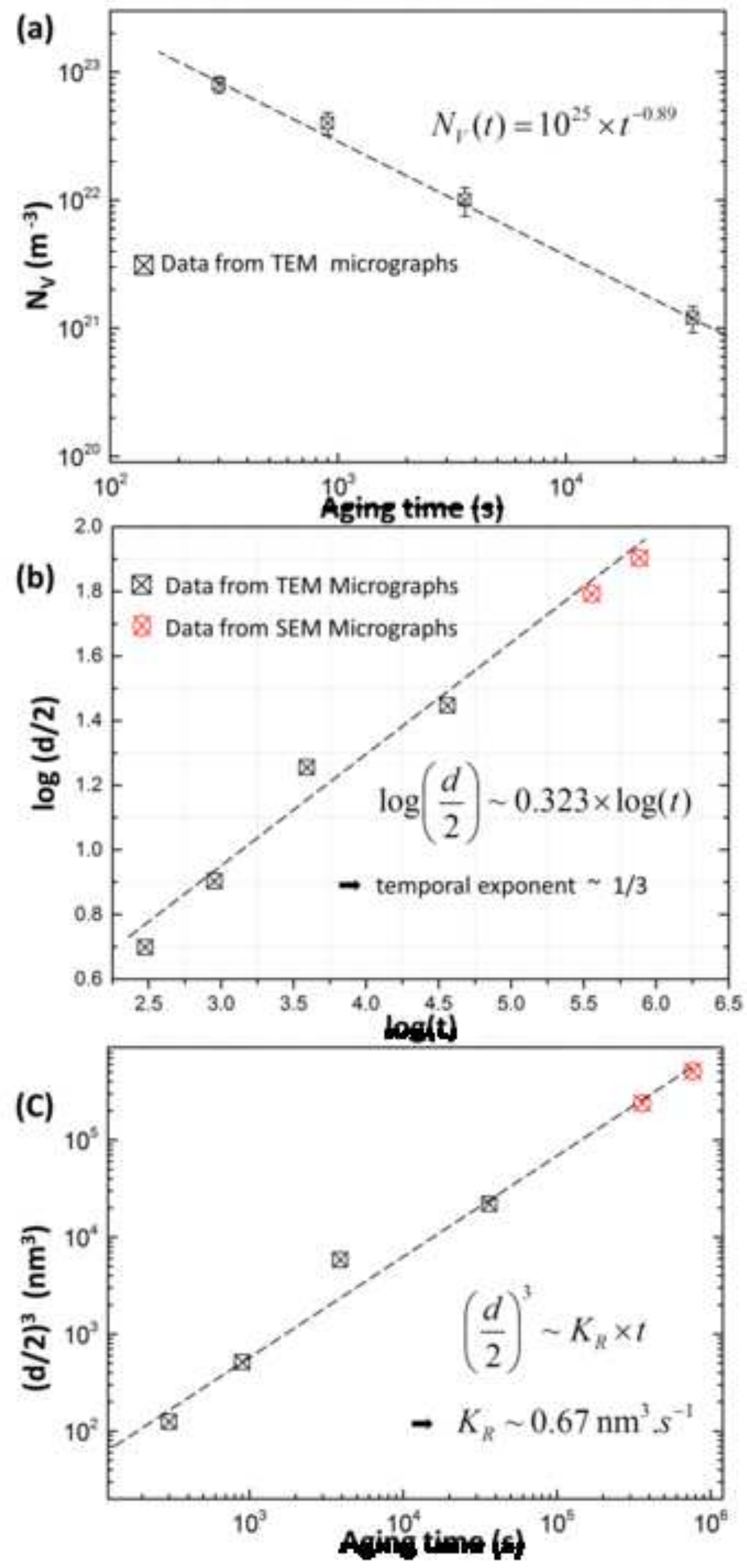
Click here to download high resolution image

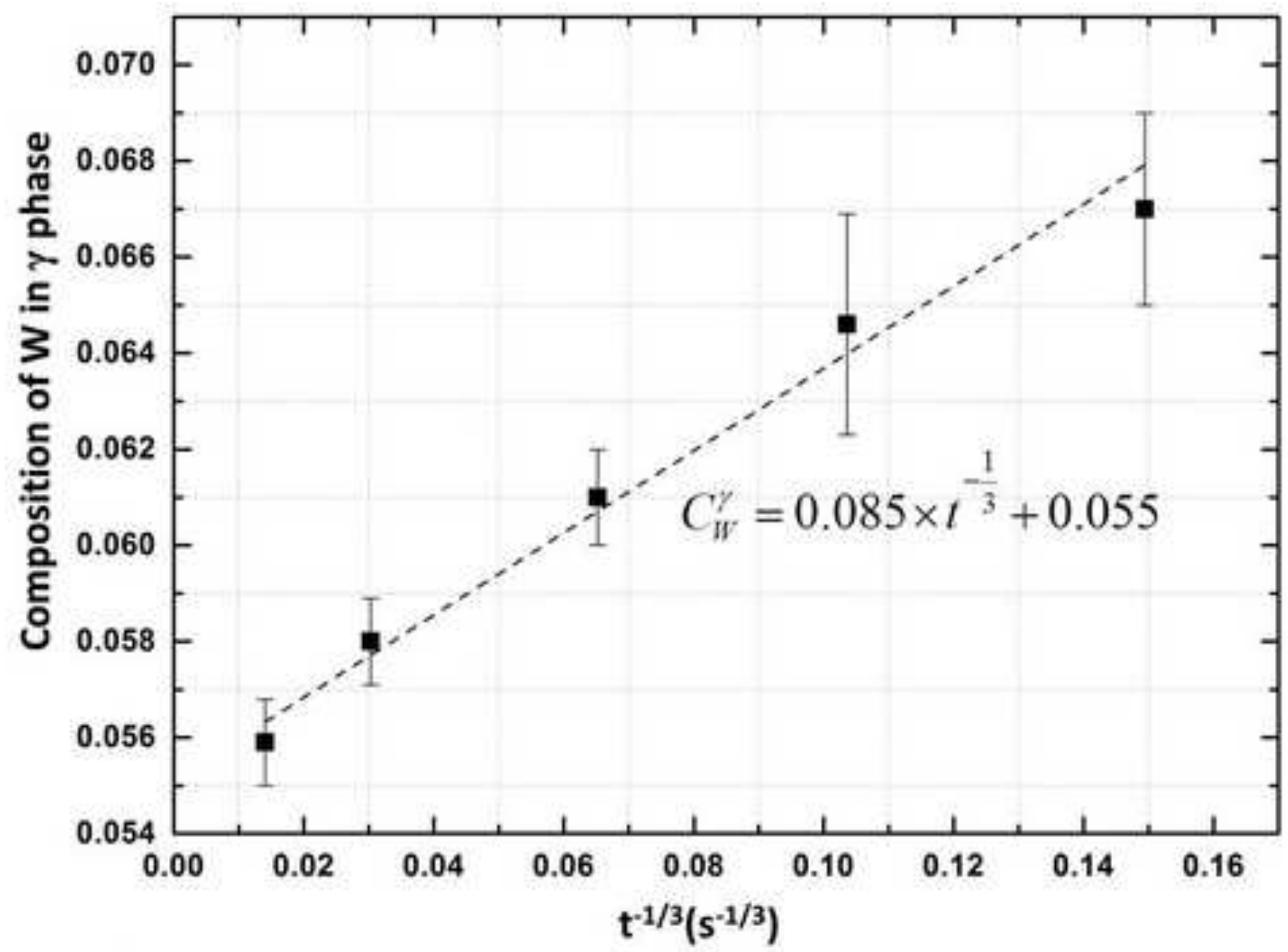

(a)

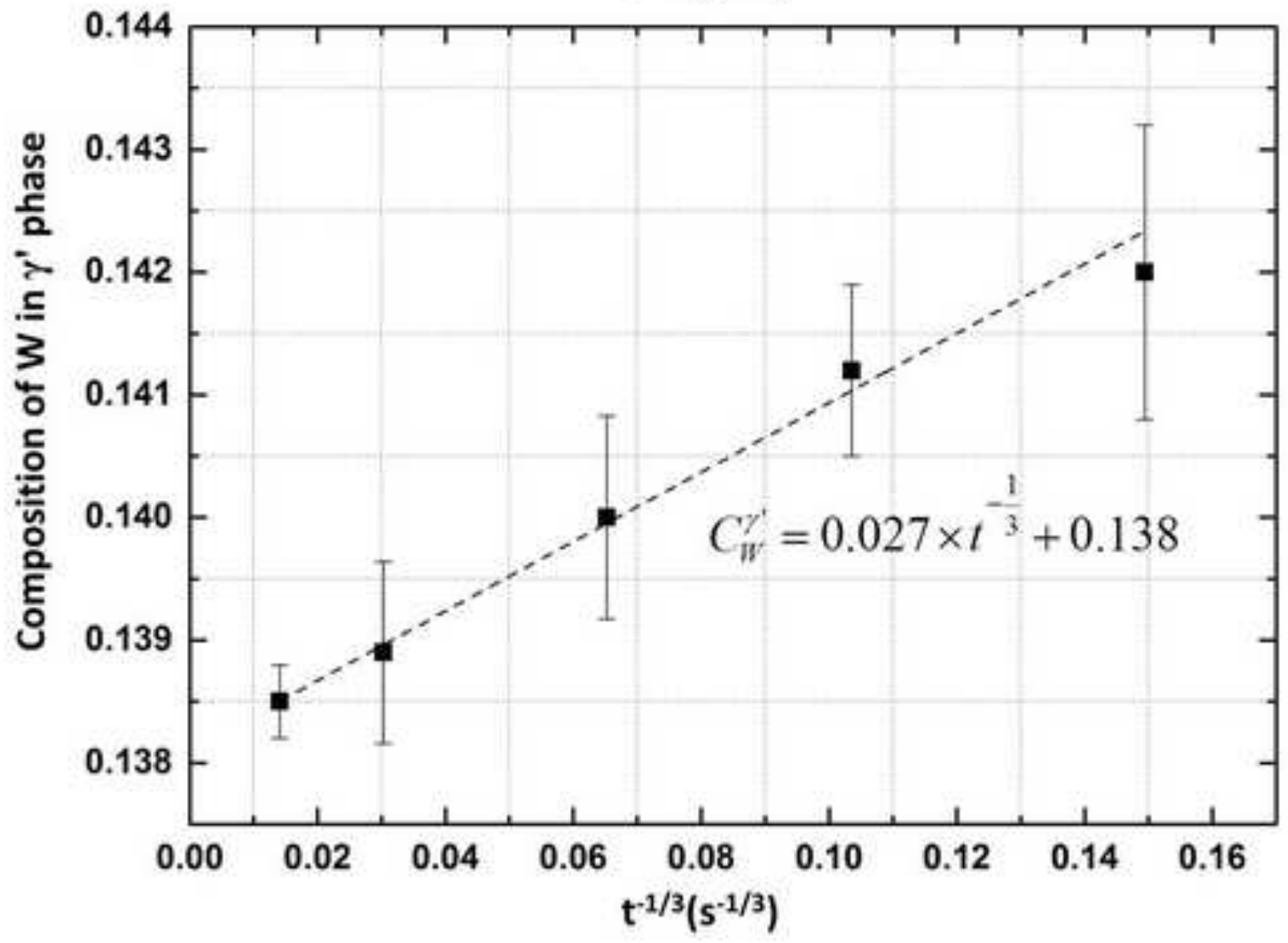

(b) 

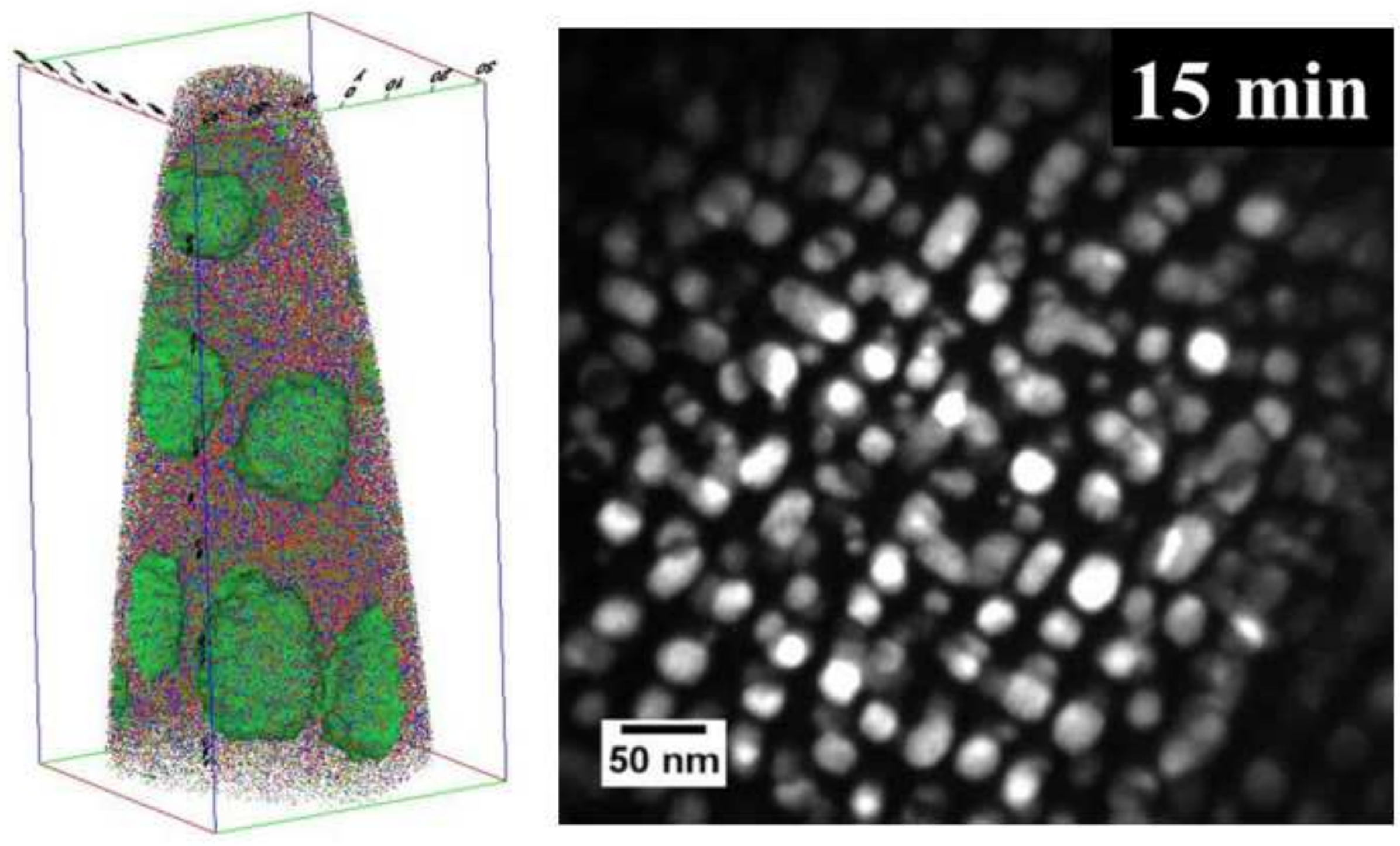